Estudios Constitucionales, Año 17, No 1, 2019, pp. 397-440

ISSN 07180195

Centro de Estudios Constitucionales de Chile Universidad de Talca

"Principio pro persona: Una revisión crítica desde el derecho internacional de los derechos humanos"

Ximena Medellín Urquiaga

\title{
PRINCIPIO PRO PERSONA: UNA REVISIÓN CRÍTICA DESDE EL DERECHO INTERNACIONAL DE LOS DERECHOS HUMANOS*
}

\author{
PRO PERSONAE PRINCIPLE: A CRITICAL ANALYSIS BASED ON \\ INTERNATIONAL HUMAN RIGHTS LAW
}

\author{
Ximena Medellín Urquiaga ${ }^{* *}$ \\ Profesor-Investigadora Titular \\ División de Estudios Jurídicos del \\ Centro de Investigación y Docencia Económicas \\ ximena.medellin@cide.edu
}

RESUMEN: Este artículo propone una revisión crítica del concepto doctrinal del principio pro persona, según ha sido desarrollado por la académica jurídica latinoamericana. El argumento central de la investigación es que la conceptualización de este principio debe atender primariamente a la lógica propia del sistema normativo que le dio origen, i. e., el derecho internacional de los derechos humanos. Lo anterior, con el fin de potenciar el proceso de recepción de las normas internacionales de derechos humanos en el marco constitucional comparado, en contraste con una visión que exacerba los conflictos normativos entre distintas fuentes válidas y vinculantes para los Estados.

ABSTRACT: This article proposes a critical review of the doctrinal concept of the pro persona principle, as it has been developed by Latin American legal studies. The central argument is that the conceptualization of this principle must primarily address the logic of its original normative system; that is, international human rights law. The foregoing, in order to enhance the process of reception of international human rights standards in comparative constitutional law, in contrast with a vision that exacerbates normative conflicts between national and international valid and binding sources of law.

PALABRAS ClaVE: Principio pro persona; derecho internacional público; Corte Interamericana de Derechos Humanos; interpretación expansiva; conflictos normativos.

KEY WORDS: Pro personae principle; international law; Inter-American Human Rights Court; extensive interpretation; conflicts of laws.

\footnotetext{
* Trabajo recibido el 12 de noviembre de 2018 y aprobado el 8 de mayo de 2019.

** Doctora en Derecho por el Instituto de Investigaciones Jurídicas de la Universidad Nacional Autónoma de México. Maestra en Derecho Internacional por la Universidad de Notre Dame. Licenciada en Derecho por la Universidad Iberoamericana, Ciudad de México.
} 


\section{INTRODUCCIÓN}

En septiembre de 2013, la Suprema Corte de Justicia de la Nación de México (“SCJN") resolvió por mayoría de votos la Contradicción de Tesis 293/2011. En esta sentencia se sostuvo la paridad jerárquica de los derechos humanos de fuente constitucional y convencional, al tiempo que se afirmó que, en caso de existir una restricción constitucional expresa a los mismos, las personas operadoras del sistema de justicia deberían sujetarse a esta. Lo anterior excluía, de inicio, la posibilidad de recurrir a una norma internacional, aun cuando la misma estableciera un estándar normativo más favorable para la protección de la persona.

Esta decisión detonó importantes críticas sobre el potencial transformador del marco constitucional mexicano en derechos humanos. La imposibilidad de recurrir a las normas convencionales, en caso de que estas establecieran un estándar de protección más alto que las normas nacionales, parecía contrario a los mandatos constitucionales expresos; en particular, al principio pro persona.

En su mayoría, dichas críticas se fundaban tanto en una propuesta conceptual específica del principio pro persona como en una necesaria aplicación secuencial de sus respectivas vertientes normativa e interpretativa. Desde esta perspectiva, el punto de partida para la argumentación de un derecho humano en un caso concreto debería ser siempre la selección del enunciado normativo más favorable, fuera de fuente constitucional o convencional (vertiente normativa del principio pro persona). Posteriormente, la norma seleccionada debería ser interpretada de forma expansiva (vertiente interpretativa). En consecuencia, la imposibilidad de seleccionar una norma internacional más favorable implicaba la corrupción del principio en su conjunto, haciendo nugatorio también el mandato de interpretación expansiva de los derechos humanos.

El debate sobre la relación entre las normas constitucionales y convencionales no es privativo de la práctica judicial mexicana. En la región latinoamericana, los dilemas sobre la incorporación del DIDH en los órdenes nacionales se han incrementado de forma importante, aun a pesar de la inclusión de cláusulas constitucionales que establecen las bases para la recepción preferente de las normas internacionales de derechos humanos. En este contexto, es importante continuar la reflexión sobre los principios que deben o pueden regir la relación entre las normas nacionales - particularmente constitucionales-y las normas convencionales que reconocen derechos humanos.

Tomando en cuenta el impacto práctico que la propuesta conceptual del principio pro persona ha tenido en la región, este artículo propone una revisión crítica 
del desarrollo dogmático de dicho principio, a partir del derecho internacional de los derechos humanos ("DIDH") y, en particular, desde la jurisprudencia de la Corte Interamericana de Derechos Humanos ("Corte IDH”). La finalidad del análisis es dilucidar si la (re)construcción del principio pro persona, a partir de la lógica propia del DIDH, puede aportar una visión distinta a la argumentación jurídica de derechos humanos. Lo anterior, con miras a delinear algunas respuestas frente a los retos aparejados con su operación en sede nacional.

La literatura especializada en la materia recurrentemente reconoce al DIDH como el fundamento normativo originario del principio pro persona. No obstante lo anterior, difícilmente se ha examinado la corrección de la propuesta conceptual desde la lógica propia de este sistema normativo. Esto no es de extrañar, considerando que, en términos generales, la incorporación del DIDH en los sistemas jurídicos nacionales no ha estado acompañada por un estudio más pormenorizado de sus dinámicas internas, así como el impacto que estas pueden tener en la relación con los sistemas jurídicos nacionales. Por el contrario, la propuesta de incorporación del DIDH tiende a centrarse en el debate de la equiparación de la calidad de las normas internacionales con las normas constitucionales o legales internas. Desde esta aproximación, el DIDH pierde sus cualidades o características intrínsecas para asumir, en el mejor de los casos, aquellas atribuidas a las normas constitucionales. Sin ahondar en un debate todavía abierto, es posible al menos cuestionar si esta "constitucionalización" automática, autómata o casi irreflexiva de las normas internacionales, puede también conducir al empobrecimiento del desarrollo dogmático o de la práctica argumentativa de los derechos humanos en sede nacional.

Con estas consideraciones en mente, este artículo se sustenta tanto en una revisión detallada de los principales estudios doctrinales latinoamericanos relacionados con el principio pro persona, como en un examen de la jurisprudencia de la Corte IDH. Específicamente, en sentencias de fondo que hacen referencia directa o indirecta a dicho principio. En este punto, es importante hacer notar que, en la práctica, la Corte IDH rara vez hace mención expresa del término "pro persona”. Por el contrario, la interpretación expansiva normalmente se vincula con referencias al artículo 29 de la $\mathrm{CADH}$ o, en su caso, al principio de la norma más favorable. En consecuencia, el análisis de la jurisprudencia de la Corte IDH se plantea desde una revisión en detalle de los argumentos avanzados por este órgano interamericano en sus propias sentencias, antes que en una búsqueda de términos específicos, normalmente vinculados con la materia de estudio. 
La primera sección del artículo propone una reconstrucción descriptiva de la evolución del concepto del principio pro persona, a través del análisis de los trabajos académicos más representativos en la materia. Esta reconstrucción busca demostrar la complejidad conceptual que entraña el desarrollo dogmático del principio. En la segunda sección del artículo se estudia, a grandes rasgos, la lógica de operación normativa del DIDH, con la finalidad de poner de relieve las particularidades del orden jurídico internacional, en tanto el posible sistema normativo que fundamenta el principio pro persona. En las secciones tercera, cuarta y quinta se propone el examen integral de la jurisprudencia interamericana respecto al principio pro persona, como base para la revisión crítica del concepto dogmático que se ha propagado a través de Latinoamérica. En la última parte se presentan algunas conclusiones generales, las cuales tienen como finalidad aportar más luces a la operación concreta del principio pro persona en las decisiones judiciales a nivel nacional, además de destacar la relevancia de analizar un concepto jurídico en los contextos normativos adecuados.

\section{LOS PROBLEMAS PRÁCTICOS DE LA OPERACIÓN DEL CONCEPTO DEL PRINCIPIO PRO PERSONA}

Durante las últimas décadas, el principio pro persona ha sido materia de importantes estudios doctrinales. El concepto en que se funda gran parte del análisis judicial y la discusión académica en Latinoamérica tiene su origen en los trabajos de autores como Mónica Pinto ${ }^{1}$, Néstor Sagüés ${ }^{2}$ o Edgar Carpio Marco ${ }^{3}$. Esta misma propuesta ha sido retomada por distintos académicos en la región, incluidos Fabian Salvioli, Humberto Henderson, Federico Robledo, Karlos Castilla, Mireya Castañeda o Gonzalo Aguilar Cavallo ${ }^{4}$.

En palabras de la jurista argentina Mónica Pinto, "[e]l principio pro homine [actualmente denominado pro persona] es un criterio hermenéutico que informa todo el derecho de los derechos humanos, en virtud del cual se debe acudir a la norma más amplia, o a la interpretación más extensiva, cuando se trata de reconocer derechos protegidos e, inversamente, a la norma o a la interpretación

\footnotetext{
1 PINTO (1997).

2 SAGÜÉS (2004).

3 Carpio (2004).

4 Salvioli (2003), Henderson (2004), Robledo (2006), Castilla (2009), Castañeda (2014), Aguilar (2016).
} 
más restringida cuando se trata de establecer las restricciones permanentes al ejercicio de los derechos humanos" 5 . Esta definición ha servido como base para una multiplicidad de estudios doctrinarios posteriores, los cuales hacen referencia explícita a la definición arriba transcrita.

Si bien el trabajo de Pinto no detalla los fundamentos de su propia propuesta, la misma tiene una incuestionable similitud con la forma en que el juez Rodolfo Piza Escalante había previamente concebido el principio pro persona. En su voto particular en la Opinión Consultiva OC-7/87 de la Corte IDH, Piza sostuvo que el principio pro persona debía entenderse como el "[...] criterio fundamental [que] [...] impone la naturaleza misma de los derechos humanos, la cual obliga a interpretar extensivamente las normas que los consagran o amplían y restrictivamente las que los limitan o restringen. [De esta forma, dicho principio] [...] conduce a la conclusión de que [la] exigibilidad inmediata e incondicional [de los derechos humanos] es la regla y su condicionamiento la excepción"6.

Con estos antecedentes, el concepto del principio pro persona se trasplantó a otros países latinoamericanos a través de distintos trabajos académicos. En este desarrollo doctrinal se plantearon las dos vertientes o directrices que, teóricamente, conformaban el principio. Según señalaran en su momento el jurista peruano Edgar Carpio Marcos o los chilenos Gonzalo Aguilar Cavallo y Humberto Nogueira Alcalá, Néstor Pedro Sagüés fue el primer doctrinario en afirmar que "el principio pro homine también comprende una 'directriz de preferencia de normas', es decir, que ante un caso a debatir, el juez (...) tendrá que aplicar la norma más favorable a la persona, con independencia de su nivel jurídico" 7 . Con esta nueva propuesta dogmática, la conceptualización del principio había pasado de ser un "criterio hermenéutico" o de interpretación, para convertirse también en un criterio de selección normativa. Lo anterior, en respuesta a uno de los problemas tradicionales de la argumentación formal de los problemas jurídicos, i. e., las colisiones normativas.

No obstante lo anterior, un examen más detallado de los primeros trabajos en que se planteó el estudio del principio pro persona develan una complejidad que no necesariamente se plasma en el debate conceptual posterior. La pregunta teórica

5 PINTO (1997), p. 163.

6 Corte Interamericana de Derechos Humanos. Exigibilidad del Derecho de Rectificación o Respuesta (1986). Opinión Separada del Juez Rodolfo E. Piza Escalante, párr. 36.

7 SAGǗÉs (2004), p. 31. 
a la que aparentemente se proponían responder dichos estudios era los retos que imponía la recepción del DIDH en sede nacional; entre ellos, los efectos de la ratificación o adhesión a tratados internacionales, su implementación legislativa a nivel nacional o la interpretación y aplicación de disposiciones de diversas fuentes normativas por parte de órganos judiciales locales.

Con base en su concepto inicial, Mónica Pinto afirmó que el principio pro persona comprendía dos "pautas" (no vertientes o directrices) de operación en el orden jurídico nacional ${ }^{8}$. La primera de ellas implicaba la "pauta hermenéutica", a través de la cual se integrarían o armonizarían las normas nacionales e internacionales que reconocen su contenido normativo9. La segunda pauta se identificaba con la "regulación jurídica" de los derechos, la cual correspondía al examen sobre la "reglamentación razonable", las "restricciones legítimas" y la suspensión de derechos en el orden nacional. En otras palabras, en tanto que la primera pauta se vinculaba directamente con los ejercicios interpretativos del DIDH en sede nacional, atendiendo a la pluralidad normativa propia del reconocimiento de los derechos humanos, la segunda pauta correspondía a acciones normalmente identificadas con los procesos de implementación legislativa de tratados internacionales.

La noción de las pautas del principio pro persona propuesta por Pinto es claramente diferente a la idea de las vertientes o directrices, por lo que podría cambiar sustantivamente la forma de entender la operación del principio a nivel nacional. Según destaca Pinto, uno de los retos cotidianos de la implementación legislativa de tratados internacionales es la armonización interna de distintas normas internacionales que establecen o reconocen estándares de protección diferenciados. En esta línea, la propia Corte IDH ha enfatizado que los Estados están obligados a tomar, como parámetro mínimo para la implementación legislativa, la disposición internacional que establezca un nivel más alto de protección para el ejercicio de los derechos humanos ${ }^{10}$. De esta forma, se refuerza la premisa de que los compromisos internacionales adoptados en virtud de tratados específicos son pisos mínimos para el

${ }^{8}$ La referencia constante al trabajo de Mónica Pinto se debe a su relevancia en la discusión teórica del principio pro persona en el contexto latinoamericano. Como se apuntó al inicio de este artículo, el trabajo de Pinto parece ser una de las primeras propuestas conceptuales sobre el tema. Más relevante aún, los estudios académicos posteriores recurrentemente hacen referencia directa al concepto propuesto por Mónica Pinto, de forma que su definición del principio pro persona se ha asumido como la base para la construcción teórica posterior.

9 PINTo (1997), pp. 164-165.

10 Véase, por ejemplo, Corte Interamericana de Derechos Humanos. La colegiación obligatoria de periodistas (1985). 
reconocimiento de los derechos humanos, que permiten la evolución del contenido normativo o ámbitos de protección a través del desarrollo de normas posteriores.

En este contexto, la idea de la selección de la norma más favorable o protectora toma un sentido distinto a la selección normativa como base para la decisión judicial en un caso concreto ${ }^{11}$. Para fines de la labor argumentativa judicial en sede nacional, la propuesta de Pinto parecería privilegiar la operación de la pauta hermenéutica del principio, a fin de privilegiar la interpretación armónica de distintos enunciados normativos que pueden reconocer (incluso con distintos estándares) un derecho humano específico.

En todo caso, es necesario reconocer que cualquiera de las propuestas sobre el concepto del principio pro persona tienen como referente la lógica de los sistemas jurídicos nacionales. En otras palabras, en los estudios dogmáticos analizados, el DIDH se piensa siempre a partir de su relación con el derecho nacional, sin necesariamente atender a las características del propio orden internacional. Nuevamente, en palabras de Mónica Pinto: "[s]in perjuicio de la autonomía de cada orden jurídico para determinar los modos de su integración, para establecer el orden jerárquico de sus normas y, por lo tanto, individualizar los criterios para resolver y superar los eventuales conflictos que puedan plantearse, la pluralidad de fuentes apuntada impone una compatibilización respecto al alcance de los derechos protegidos y las obligaciones asumidas por los Estados"12. Esa compatibilización se propone, sin embargo, desde una inercia (posiblemente desproporcionada) de la argumentación jurídica a nivel nacional. Como resultado, la posible relación del principio pro persona con los debates sobre la selección normativa o la solución de antinomias se entiende desde la lógica de un sistema que no es su origen o fundamento, al menos en opinión de distintos autores.

\section{EL PRINCIPIO PRO PERSONA A LA LUZ DE LAS DINÁMICAS NORMATIVAS DEL DERECHO INTERNACIONAL DE LOS DERECHOS HUMANOS}

El análisis del principio pro persona en el contexto del DIDH debe partir del reconocimiento de las características del mismo, en tanto una rama del derecho

11 La relevancia de seleccionar la norma internacional más protectora, como parámetro para la implementación legislativa a nivel nacional, no excluye tampoco la posibilidad de realizar un ejercicio de armonización entre el derecho nacional e internacional, a fin de construir las mejores posibilidades de protección para las personas. $\mathrm{Al}$ respecto, véase Corte Interamericana de Derechos Humanos. Propuesta de modificación a la Constitución Politica de Costa Rica relacionada con la naturalización (1984), párr. 38.

12 Pinto (1997), pp. 165-171. 
internacional público (“DIP”). De manera particular, en esta sección se analizarán los fundamentos generales de la relación de normas internacionales, así como la importancia de los principios de interpretación del DIDH. La premisa inicial del análisis es que las características que distinguen al DIDH deberían impactar no solo la práctica argumentativa de los órganos especializados, sino también los conceptos dogmáticos que sirvan para estructurar, explicar y guiar su operación, incluido el principio pro persona.

Tal como es ampliamente reconocido, la forma de gobernanza internacional ha resultado en un orden jurídico que difiere de manera importante de los sistemas identificados con la tradición codificadora. La dinámica difusa de creación normativa internacional contrasta con la operación de un poder legislativo central, el cual funda su autoridad en una norma superior que organiza el sistema de producción de fuentes jurídicas. Consecuentemente, la estructura o dinámicas del DIP no pueden proponerse desde la relación jerárquica que caracteriza a muchos de los órdenes jurídicos nacionales. Por el contrario, en la actualidad se reconoce que, junto con las normas generales del DIP, se han desarrollado otros principios o reglas internacionales, primarias o secundarias, que se agrupan o vinculan desde una lógica primordialmente funcional; es decir, atendiendo al objeto o finalidad de las mismas.

En este sentido, el DIP se asimila a una especie de redes normativas ${ }^{13}$, estructuradas a través de nodos diferenciados por la función de las normas que los componen. Estos nodos son conocidos en la jerga jurídica internacional como regímenes autónomos ${ }^{14}$. En el estado actual del debate, el DIDH se identifica como uno de los principales regímenes que conforman o integran el DIP.

Esta teorización sobre la estructura del DIP, desarrollada principalmente alrededor de los debates sobre la fragmentación, ha buscado revertir la idea de un régimen normativo primitivo que adolece de la sistematicidad necesaria de los órdenes jurídicos nacionales ${ }^{15}$. Sin ahondar en problemas que no aportan sustantivamente al tema central de este artículo, es importante reconocer que, más allá de una explicación precisa sobre la forma de organización del DIP, existen aún importantes preguntas sobre las consecuencias de su estructura misma. Posiblemente, una de las más relevantes sea cómo deben enfrentarse los supuestos

13 Simma y Pulkowski (2006), pp. 483-529.

14 Comisión de Derecho Internacional (2006).

15 Koskenniemi y Leino (2002), pp. 553-579. 
en que normas del DIP general y/o de distintos regímenes autónomos establecen obligaciones o mandatos de actuación aparentemente contradictorios ${ }^{16}$.

De acuerdo con el informe de la Comisión de Derecho Internacional de las Naciones Unidas ("CDI-ONU”) sobre fragmentación del DIP, existen solo tres tipos de normas que pueden considerarse jerárquicamente superiores, aunque no en el sentido tradicionalmente asociado con este término. Dichos tipos de normas son: (i) las prohibiciones de ius cogens; (ii) las obligaciones erga omnes, y (iii) las obligaciones que se derivan de la Carta de las Naciones Unidas, en virtud del artículo 103 de dicho instrumento ${ }^{17}$. En consecuencia, si en un caso concreto una obligación de fuente internacional se contrapone con un mandato establecido en alguna de estas normas superiores, la inobservancia de la primera no conllevará la responsabilidad del Estado. Sin embargo, a diferencia de muchos sistemas normativos nacionales, este tipo de contradicción no resultará en la invalidez general de la disposición contraria, sino solo en una forma de "inaplicación".

Por lo que toca a la relación entre otras normas de fuente internacional, la operación del sistema deberá privilegiar interpretaciones que armonicen distintas disposiciones normativas, de forma que se asegure la satisfacción de los derechos y el cumplimiento de las obligaciones. En palabras de la CDI-ONU, "[e]n el Derecho Internacional hay una fuerte presunción en contra de los conflictos normativos. La interpretación de tratados internacionales es diplomacia y la función de la diplomacia es evitar o mitigar los conflictos. Lo anterior se extiende también a la adjudicación". ${ }^{18}$

De esta forma, el orden jurídico internacional rechaza, al menos en principio, las soluciones abstractas o fuera de contexto, sobre la validez o invalidez de ciertas disposiciones jurídicas. En esta lógica, los principios de temporalidad o especialidad funcionan de manera distinta que en muchos órdenes jurídicos nacionales ${ }^{19}$. Aquellos no determinan, como se dijo, la invalidez o, incluso, la inaplicación de una disposición internacional frente a otra en abstracto. Solo en ciertos supuestos, particularmente cuando la intención de las partes es claramente la modificación de sus derechos y obligaciones recíprocos, se podrá concluir el efecto invalidante

\footnotetext{
16 JENKS (1953), pp. 401-453.

17 Comisión de Derecho Internacional (2006), párrs. 327 y ss.

18 Ibídem, párr. 37. [Traducción por la autora].

19 Ibídem, párrs. 258 y ss.
} 
de una norma posterior. En el caso de las normas especiales, el propio informe de la CDI-ONU reconoce que las mismas deben siempre interpretarse a la luz de un contexto político-jurídico más amplio, determinado por otras normas especiales $y$, en particular, por el propio DIP general.

El problema de la fragmentación de DIP no solo se origina en el contraste de las disposiciones normativas per se, sino también a través la discrepancia que puede resultar de la multiplicidad de interpretaciones judiciales ${ }^{20}$. Lo anterior, como consecuencia directa del incremento expansivo de tribunales internacionales durante las últimas décadas ${ }^{21}$. Frente a esta dimensión particular del fenómeno de la fragmentación del DIP, la respuesta ha sido destacar la importancia de los principios o reglas de interpretación de las normas internacionales, cuya correcta aplicación debería dotar al sistema de una coherencia interna adicional.

Como es ampliamente conocido, el fundamento tradicional de la regla de interpretación internacional es el artículo 31 de la Convención de Viena sobre el Derecho de los Tratados ("CVDT"). De manera subsidiaria, la propia CVDT establece que, en caso de que la interpretación con base en el artículo 31 "deje ambiguo u obscuro el sentido [de la disposición] o conduzca a un resultado manifiestamente absurdo o irrazonable”, se podrá recurrir a los trabajos preparatorios $\mathrm{u}$ otros medios de interpretación complementarios ${ }^{22}$.

Dentro de estas reglas generales, el DIDH ha enfatizado ciertos principios de interpretación específicos, que lo distinguen también de la argumentación normativa planteada desde el DIP general. Sobre este punto, el informe de la CDI-ONU destacó que el razonamiento de los tribunales internacionales de derechos humanos refuerza la naturaleza propia de los tratados en la materia, así como de sus mecanismos particulares de protección, para justificar una práctica interpretativa sustantivamente distinta de aquella desarrollada por otros órganos internacionales, incluida la $\mathrm{CIJ}^{23}$. Esta especialidad en la interpretación refuerza nuevamente la calidad del DIDH como un régimen autocontenido. En palabras de la CDI-ONU, "un sistema autocontenido [puede tener] efectos predominantemente al establecer guías interpretativas y direcciones que en cierta forma se

20 Comisión de Derecho Internacional (2006), párrs. 49-52.

21 Koskenniemi y Leino (2002).

22 Convención de Viena sobre Derecho de los Tratados (1969), artículo 32.

23 Comisión de Derecho Internacional (2006), párrs. 49-52. 
separa de las reglas del derecho [internacional] general"24. En el mismo sentido, la Corte IDH ha reiterado que

[la] jurisprudencia [interamericana está basada] en el carácter especial de la [CADH] en el marco del Derecho Internacional de los Derechos Humanos. Dicha Convención, así como los demás tratados de derechos humanos, se inspiran en valores comunes superiores (centrados en la protección del ser humano), están dotados de mecanismos especificos de supervisión, se aplican de conformidad con la noción de garantía colectiva, consagran obligaciones de carácter esencialmente objetivo, y tienen una naturaleza especial, que los diferencian de los demás tratados, los cuales reglamentan intereses recíprocos entre los Estados Partes ${ }^{25}$.

En síntesis, en tanto una rama del DIP, es importante reconocer que el DIDH se funda en una lógica que privilegia la interpretación armónica o sistémica, particularmente frente a posibles conflictos normativos. Aun reconociendo las jerarquías explícitas o implícitas del DIP, la dinámica contraconflictual propia de este sistema jurídico ha impactado también la forma de concebir las normas internacionales de derechos humanos. Lo anterior implica una preferencia natural por los debates relacionados con los principios, prácticas o formas de interpretación normativa, antes que por criterios de selección normativa o de solución de antinomias, según operan tradicionalmente en los sistemas codificados. Estas consideraciones ponen en tela de juicio, de inicio, la relevancia o el peso de las dos vertientes propuestas a través del concepto latinoamericano del principio pro persona y, mucho más, el argumento sobre su aplicación necesariamente secuencial.

\section{El PRINCIPIO PRO PERSONA EN EL MARCO DEL Sistema Interamericano de Derechos Humanos}

Con base en el examen general de las dinámicas normativas propias del DIDH, el punto de partida natural para el análisis de la operación del principio pro persona en el marco del Sistema Interamericano de Derecho Humanos ("SIDH”) es el artículo 29 de la Convención Americana sobre Derechos Humanos ("CADH”). Tal como lo ha señalado la Corte IDH, esta disposición contiene un intricado

\footnotetext{
24 Ibídem, párr. 132.

25 Corte Interamericana de Derechos Humanos. Masacre de Mapiripán Vs. Colombia (2005), párr. 106. Véase también Corte Interamericana de Derechos Humanos. Ivcher Bronstein Vs. Perú (1999), párr. 42; Corte Interamericana de Derechos Humanos. Tribunal Constitucional Vs. Perú (1999), párr. 41.
} 
sistema de principios específicos que sientan las bases para un diálogo activo entre la $\mathrm{CADH}$ y otras normas de derechos humanos, cualquiera que sea su origen nacional o internacional-o naturaleza-constitucionales, legales, convencionales, consuetudinarias o, incluso, principios generales del derecho-.

En la jurisprudencia interamericana, el artículo 29 de la $\mathrm{CADH}$ se ha utilizado en diversos contextos y con distintos efectos. En la decisión de fondo del caso Apitz Barbera y otros contra Venezuela, la Corte IDH realizó un recuento puntual de distintos casos en que había invocado las reglas contenidas en el artículo citado, con base en los cuales se identificaron tres ámbitos distintos para su uso. El primero se refiere a la determinación del contenido de los derechos reconocidos en la CADH, lo que también implica establecer el alcance de sus restricciones, así como la interpretación de "los derechos convencionales a la luz de los derechos que derivan de la forma democrática representativa de gobierno"26. En segundo lugar, el artículo 29 de la CADH debe servir como fundamento de los criterios o reglas generales de interpretación de los derechos humanos, desde los que "se ha desarrollado el principio de 'aplicación de la norma más favorable a la tutela de los derechos humanos' como derivado del artículo 29.b) [nota omitida] y la prohibición de privar a los derechos de su contenido esencial como derivado del artículo 29.a) [nota omitida]"27. En tercer lugar, la disposición referida debe servir para ampliar el alcance de la competencia consultiva de la propia Corte IDH, al habilitar la interpretación de otros tratados internacionales, en tanto una forma de garantía de los derechos humanos ${ }^{28}$.

Sin minimizar la relevancia de la función consultiva de la Corte IDH, el centro del análisis de esta investigación será la forma en que dicho tribunal ha utilizado el artículo 29 de la CADH para (i) dotar de contenido los derechos y limitar sus restricciones, así como para (ii) consolidar los principios de interpretación particularmente relevantes para los tratados en materia de derechos humanos. Sobre este último punto, es pertinente destacar que la Corte IDH ha sostenido que "en el marco de [su] jurisdicción contenciosa [...], el incumplimiento de los principios de interpretación que se derivan del artículo 29 [...] sólo podrían generar la violación del derecho que haya sido indebidamente

26 Corte Interamericana de Derechos Humanos. Apitz Barbera y otros ("Corte Primera de lo Contencioso Administrativo") Vs. Venezuela (2008), párr. 217.

27 Ibídem, párr. 218.

28 Ibídem, párr. 219. 
interpretado a la luz de dichos principios" 29 . Este criterio impone una carga argumentativa específica a los tribunales nacionales. Consecuentemente, en cumplimiento del mandato impuesto por la $\mathrm{CADH}$ no sería suficiente que los órganos nacionales invoquen las normas internacionales relevantes, sino que deberán utilizar también los principios de interpretación que se derivan del artículo 29 convencional.

Según se apuntó antes, sin alejarse completamente de la regla general del artículo 31 de la CVDT, los mecanismos internacionales de derechos humanos $y$, en específico, la Corte IDH han desarrollado al menos cuatro principios de interpretación particularmente relevantes para fines de esta investigación: (i) la interpretación armónica o sistémica ${ }^{30}$; (ii) la interpretación evolutiva ${ }^{31}$; (iii) la interpretación consensual, y (iv) la interpretación expansiva. El análisis conceptual de cada uno de estos principios excede el objetivo de este trabajo. En todo caso, es importante reconocer que, según la jurisprudencia internacional, los mismos se sustentan en una lógica común de protección efectiva de los derechos humanos, en tanto la vocación o función de las normas correspondientes.

En la práctica, es difícil diferenciar con total precisión el ámbito de aplicación o alcance de cada uno de los principios enumerados. La interpretación expansiva del contenido de los derechos en muchos casos implica reconocer el contexto social

29 Ibídem, párr. 221. [Énfasis añadido].

30 La interpretación armónica establece un vínculo no solo con las normas internas de cada sistema regional, sino que se expande a una visión más amplia e integral del DIDH. Lo anterior, con miras a dotar de más congruencia al sistema internacional y, sobre todo, asegurar la protección más efectiva de los derechos humanos. En palabras del juez Piza Escalante, los criterios de interpretación "apuntan también a la necesidad de interpretar e integrar cada norma de la $[\mathrm{CADH}]$ utilizando los principios yacentes, o subyacentes o suprayacentes en otros instrumentos internacionales, en los propios ordenamientos internos y en las tendencias vigentes en materia de derechos humanos, todos los cuales se encuentran en alguna medida incorporados a la [CADH] misma por virtud del citado artículo 29, cuya amplitud innovadora no tiene paragón en ningún otro documento internacional". Corte Interamericana de Derechos Humanos. Propuesta de modificación a la Constitución Política de Costa Rica relacionada con la naturalización (1984). Voto concurrente del juez Piza Escalante.

31 Corte Interamericana de Derechos Humanos. Comunidad Mayagna (Sumo) Awas Tingni Vs. Nicaragua (2001), párrs. 146-148; Corte Interamericana de Derechos Humanos. Comunidad Indígena Yakye Axa Vs. Paraguay (2005), párr. 125; Corte Interamericana de Derechos Humanos. Masacre de Mapiripan vs. Colombia (2005), párr. 106; Corte Interamericana de Derechos Humanos. Atala Riffo y niñas Vs. Chile (2012), párr. 83. Esta forma de entender la interpretación de los tratados internacionales es claramente coincidente con la doctrina del "propósito emergente", según la cual "el objeto y fin que determina la verdadera interpretación de un tratado serán aquéllos que existan al momento de la interpretación, no al momento de su conclusión”. JACOBS (1969), p. 320. 
o las condiciones de vida de una comunidad precisa, al tiempo que se propone una armonización interpretativa con otras normas internacionales, nacionales e, incluso, consuetudinarias ${ }^{32}$. En otros casos, la misma interpretación sistémica de las normas internacionales de derechos humanos puede ser la base para afirmar su interpretación evolutiva, a fin de asegurar la protección más amplia a las personas.

Un ejemplo interesante de esta aproximación a la interpretación integral de derechos humanos es la sentencia de la Corte IDH en el caso Atala y niñas contra Chile. En la sentencia de fondo respectiva, la Corte IDH reconoció que, si bien la $\mathrm{CADH}$ "no contiene una definición explícita del concepto de 'discriminación”"33, el artículo 1.1 convencional debía interpretarse de forma armónica con otros instrumentos internacionales, así como con la doctrina especializada en la materia, a fin de dotarlo de un contenido más preciso. Con estas bases, la Corte IDH estableció que la referencia a "otra condición social" en el artículo 1.1 de la CADH debe ser interpretada atendiendo a "la evolución de los tiempos y las condiciones de vida actuales[,] [...] en la perspectiva de la opción más favorable a la persona y de la evolución de los derechos fundamentales en el derecho internacional contemporáneo [...] según el principio de la norma más favorable al ser humano"34. Con estas bases, la Corte IDH concluyó que la orientación sexual debe tenerse como una categoría incluida en "otra condición social".

El énfasis interpretativo del DIDH conduce a una preferencia natural por la construcción dinámica del contenido de los derechos humanos. Esta lógica implica reconocer que ninguna disposición normativa per se determina en su totalidad el contenido de un derecho. Por el contrario, los mismos normalmente deben construirse a partir de un diálogo constante entre una pluralidad de disposiciones que reconocen distintos elementos o dimensiones de un mismo derecho. En este ejercicio argumentativo se debe considerar, además, el impacto jurídico de contextos sociales, políticos o económicos que condicionan el ejercicio de los derechos, a fin de potenciar su eficacia. Esta propuesta, fuertemente argumentativa, está lejos de la lógica jurídica centrada en la selección de una sola norma como base para el análisis de casos concretos de violaciones de derechos humanos, según se explicará en la siguiente sección.

32 Véase, por ejemplo, Corte Interamericana de Derechos Humanos. Pueblo Indígena Kichwa de Sarayaku Vs. Ecuador (2012), párrs. 161-165.

33 Corte Interamericana de Derechos Humanos. Atala Riffo y niñas Vs. Chile (2012), párr. 81.

34 Ibídem, párrs. 84-86. 


\section{La interPRETACiÓN MÁS FAVORABLE EN LA JURISPRUdENCIA DE LA CORTE InTERAmericana De Derechos Humanos}

Con base en este acercamiento inicial a los principios de interpretación de los derechos humanos, en esta sección se analizará de manera particular la forma en que la Corte IDH ha operado el principio pro persona casos concretos. De una lectura general de la jurisprudencia interamericana es posible identificar tres espacios argumentativos específicos en los cuales el principio pro persona ha tenido una relevancia particular. El primero de ellos implica la interpretación armónica de las disposiciones que reconocen los derechos humanos, a fin de expandir el contenido normativo de los derechos. Como complemento necesario de este tipo de argumentación, en segundo lugar, la Corte IDH ha realizado una interpretación expansiva o amplia del alcance de las obligaciones estatales, en tanto una condición fundamental para la exigibilidad de los derechos. En tercer lugar, el principio pro persona se ha utilizado para excluir cualquier interpretación que conduzca a engrosar las limitaciones a los derechos humanos. En términos prácticos, lo anterior implica un ejercicio que expande el ámbito de protección de los derechos, tomando como referente tanto a la $\mathrm{CADH}$ como otras normas internacionales o nacionales.

\subsection{Interpretación expansiva del contenido normativo de los derechos humanos}

Durante más de treinta años, la Corte IDH ha desarrollado una amplia jurisprudencia, a través de la cual ha dotado de contenido a normas jurídicas que, de otra forma, parecerían simples enunciados abstractos de difícil aplicación en casos concretos. De esta manera, los derechos humanos toman sentido no solo en su contenido, sino en la posibilidad de exigibilidad a nivel nacional e internacional.

Como se destacó antes, la interpretación expansiva de los derechos, normalmente identificada con el principio pro persona, conlleva también la interpretación armónica, evolutiva y consensual de las disposiciones relevantes. En todo caso, es plausible sostener que esa interpretación expansiva implica, por ejemplo: (i) afirmar la titularidad y exigibilidad de un derecho a personas que se sitúan en condiciones especiales, no explícitamente contempladas en la disposición normativa; (ii) adecuar las condiciones del ejercicio del derecho a la realidad fáctica o a los contextos sociales, políticos o económicos determinados, así como (iii) reconocer posiciones, bienes o servicios que no están explícitamente enun- 
ciados en un artículo convencional, como parte del contenido de un derecho. En algunos supuestos extremos, la Corte IDH ha incluso llegado a reconocer la existencia de algunos derechos innominados, que considera implícitamente reconocidos en la propia $\mathrm{CADH}^{35}$.

Este tipo de argumentación se fundamenta, antes que nada, en una interpretación que privilegia la interacción de la $\mathrm{CADH}$ con otras normas internacionales o nacionales. El creciente número de normas nacionales, regionales o universales -sean convencionales, consuetudinarias o de soft law- utilizadas por la Corte IDH para la interpretación armónica de disposiciones de la CADH hace casi imposible un recuento detallado de las mismas. Máxime considerando que ese no es el objetivo primario de este trabajo. Sin embargo, resulta oportuno plantear algunos escenarios concretos que sirvan para entender mejor la operación de la interpretación más favorable en la Corte IDH.

Así, por ejemplo, como parte del análisis de la privación arbitraria del derecho a la vida, la Corte IDH ha recurrido a instrumentos universales, como el Código de conducta para funcionarios encargados de hacer cumplir la ley ${ }^{36} \mathrm{o}$ los Principios Básicos sobre el Empleo de la Fuerza y de Armas de Fuego por los Funcionarios Encargados de Hacer Cumplir la Ley, a fin de determinar el marco de análisis de convencionalidad del uso de la fuerza letal ${ }^{37}$. En contraste, cuando la privación de la vida se ha dado en contextos de conflictos armados de carácter no internacional, la Corte IDH ha utilizado como marco de referencia para la interpretación del artículo $4^{\circ}$ de la $\mathrm{CADH}$ diversas normas relevantes del derecho internacional humanitario ${ }^{38}$. Este mismo cuerpo normativo ha sido utilizado para interpretar expansivamente

35 Probablemente, el ejemplo más concreto de esta práctica es el derecho a la identidad. A partir del caso Gelman contra Uruguay, la Corte IDH ha reconocido que la sustracción ilegal de la (entonces) menor María Macarena Gelman "afectó lo que se ha denominado el derecho a la identidad, que, si bien no se encuentra expresamente contemplado en la Convención, en las circunstancias del presente caso es posible determinarlo sobre la base de lo dispuesto por [distintos instrumentos internacionales y legislación o jurisprudencia comparada latinoamericana]". Corte Interamericana de Derechos Humanos. Gelman Vs. Uruguay (2011), párr. 122. Sobre la construcción de este mismo derecho, véase, además, Corte Interamericana de Derechos Humanos. Personas dominicanas y haitianas expulsadas Vs. República Dominicana (2014), párr. 266.

36 Corte Interamericana de Derechos Humano. Nadege Dorzema y otros Vs. República Dominicana (2012), párr. 78.

37 Corte Interamericana de Derechos Humanos. Montero Aranguren y otros (Retén de Catia) Vs. Venezuela (2006), párr. 69; Corte Interamericana de Derechos Humanos. Nadege Dorzema y otros Vs. República Dominicana (2012), párr. 78.

38 Véase, por ejemplo, Corte Interamericana de Derechos Humanos. Bámaca Velásquez Vs. Guatemala (2000), párrs. 207-209; Corte Interamericana de Derechos Humanos. Masacre de Santo Domingo Vs. 
el contenido de otros derechos que requieren también protección en contextos de conflicto armado, tales como el derecho a la propiedad ${ }^{39}$.

De la misma forma, la Corte IDH ha podido dotar su interpretación con una creciente perspectiva de género, a través de la referencia a instrumentos como la Convención Interamericana para Prevenir, Sancionar y Erradicar la Violencia contra la Mujer "Convención de Belem Do Para"40, la Convención sobre la Eliminación de Todas las Formas de Discriminación Contra la Mujer 41 , la Declaración sobre la eliminación de la violencia contra la mujer de la Asamblea General de las Naciones Unidas $^{42}$, la Plataforma de Acción de la Conferencia Mundial sobre la Mujer de Beijing ${ }^{43}$, la Declaración sobre derechos humanos, orientación sexual e identidad de género ${ }^{44}$, así como los Principios de Yogyakarta sobre la aplicación del derecho internacional de los derechos humanos en relación con la orientación sexual y la identidad de género ${ }^{45}$. La integración de la perspectiva de género en la interpretación de los derechos reconocidos en la CADH denota no solo un acoplamiento a la evolución social en la región, sino un desarrollo de la propia jurisprudencia latinoamericana. En sus primeras épocas, la Corte IDH adoleció de esta perspectiva, lo cual representó un obstáculo jurídico para el análisis integral de las violaciones planteadas en algunos $\operatorname{casos}^{46}$.

Colombia (2012), párrs 187 y ss.; Corte Interamericana de Derechos Humanos. Cruz Sánchez y otros Vs. Perú (2015), párr. 270-279.

39 Corte Interamericana de Derechos Humanos. Masacres de Ituango Vs. Colombia (2006), párrs. 179-183.

40 Corte Interamericana de Derechos Humanos. Penal Miguel Castro Castro Vs. Perú (2006), párr. 292; Corte Interamericana de Derechos Humanos. González y otras ("Campo Algodonero") Vs. México (2009), párrs. 225 y ss.; Corte Interamericana de Derechos Humanos. Fernández Ortega y otros Vs. México (2010), párr. 118; Corte Interamericana de Derechos Humanos. Rosendo Cantú y otra Vs. México (2010), párr. 108.

41 Corte Interamericana de Derechos Humanos. Artavia Murillo y otros (“Fecundación in vitro") Vs. Costa Rica (2012), párrs. 227 y 228.

42 Corte Interamericana de Derechos Humanos. González y otras (“Campo Algodonero”) Vs. México (2009), párr. 254.

43 Ibídem, párr. 254.

44 Corte Interamericana de Derechos Humanos. Atala Riffo y niñas Vs. Chile (2012), párr. 90.

45 Corte Interamericana de Derechos Humanos. Duque Vs. Colombia (2016), párr. 110.

46 Probablemente la decisión más controvertida por la ausencia de perspectiva de género sea la sentencia de fondo en el caso Loayza Tamayo contra Perú. En la misma, la Corte IDH determinó la violación al derecho a la integridad personal al establecerse la comisión de actos de tortura, pero no tuvo como probada la violencia sexual de la que había sido víctima María Elena Loayza Tamayo. Véase Corte Interamericana de Derechos Humanos. Loayza Tamayo Vs. Perú (1997). Para una crítica de esta resolución, en contraste con otras decisiones de la propia Corte IDH, véase, por ejemplo, Quintana (2008), pp. 301-313. 
En conjunto con la interpretación a la luz de instrumentos internacionales, la Corte IDH ha recurrido al examen de la legislación nacional de un Estado e, incluso, a la costumbre de determinados pueblos indígenas, con el objetivo de establecer el contenido de algunos derechos en particular ${ }^{47}$. Por ejemplo, en la sentencia de fondo de Cinco Pensionistas contra Perú, la Corte IDH concluyó, con base en la legislación nacional peruana, que la pensión nivelada era un derecho adquirido que había sido integrado al patrimonio de los peticionarios. Por ende, un cambio sustantivo en la misma constituía una violación al derecho a la propiedad, reconocido en el artículo 21 de la $\mathrm{CADH}^{48}$. En un ejercicio aún más expansivo, en el caso Mayagna (Sumo) Awas Tingni contra Nicaragua, la Corte IDH estableció que el artículo 21 de la $\mathrm{CADH}$ debía interpretarse de forma que abarcara el derecho a la propiedad comunal del pueblo indígena, atendiendo tanto a la legislación nacional nicaragüense como al derecho consuetudinario de los propios pueblos ${ }^{49}$.

La incorporación de legislación nacional para la interpretación expansiva de los derechos no se ha limitado únicamente al examen de las normas locales del Estado demandado. Existen ejemplos en que la Corte IDH ha recurrido a un estudio de derecho comparado para establecer el estado de la cuestión entre los países latinoamericanos. Lo anterior, a fin de determinar el alcance de la protección de un derecho en particular dentro de la región. Un ejemplo de esta práctica, asimilable a la interpretación consensual desarrollada por la Corte Europea de Derechos Humanos, es el caso Duque contra Colombia. En el mismo, se analizó tanto la legislación como algunos criterios judiciales de México, Uruguay, Argentina, Brasil, Chile o Estados Unidos de América, en relación con la pensión de sobrevivencia de las parejas del mismo sexo ${ }^{50}$. Con estas bases, la Corte IDH

\footnotetext{
47 Sobre este punto, es importante recordar que, a la letra, el artículo 29.b de la CADH establece que ninguna de sus disposiciones podrá ser interpretada de forma que limite "el goce y ejercicio de cualquier derecho o libertad que pueda estar reconocido de acuerdo con las leyes de cualquiera de los Estados Partes o de acuerdo con otra convención en que sea parte uno de dichos Estados". [Énfasis añadido]. Con esta referencia expresa a los derechos reconocidos en la legislación nacional o en otras convenciones internacionales, la Corte IDH tiene un fundamento jurídico claro para realizar una integración armónica amplia sobre el contenido de los derechos reconocidos en la propia CADH.

48 Corte Interamericana de Derechos Humanos. Cinco Pensionistas vs. Perú (2003), párrs. 101 y 102.

49 Corte Interamericana de Derechos Humanos. Comunidad Mayagna (Sumo) Awas Tingni Vs. Nicaragua (2001), párrs. 146-151.

50 Corte Interamericana de Derechos Humanos. Duque Vs. Colombia (2016), párrs. 113-118.
} 
determinó la violación al derecho a la igualdad, reconocido en el artículo 24 de la $\mathrm{CADH}^{51}$.

En la medida en que los casos bajo el conocimiento de la Corte IDH se han tornado fácticamente más complejos, este tribunal internacional también ha evolucionado en su forma de argumentar los derechos relevantes. En la actualidad, la interpretación expansiva se conecta de forma constante con una argumentación que destaca la interdependencia de los derechos. Por ejemplo, en el caso Artavia Murillo y otros contra Costa Rica, la Corte IDH concluyó que el derecho de las personas a decidir libremente tener hijos biológicos a través del acceso a técnicas de reproducción asistida, forma parte del ámbito de los derechos a la integridad personal, a la libertad personal, a la vida privada y familiar, en relación con los derechos a la salud, a la reproducción y a beneficiarse del desarrollo tecnológico, entendidos desde una perspectiva amplia y en operación interrelacionada ${ }^{52}$. Es oportuno destacar que, en este caso, la Corte IDH no sostuvo la existencia de un derecho innominado o implícito, sino la posibilidad de generar un espacio específico de protección que responda de manera más fehaciente a los hechos planteados por el caso. Lo anterior, como se señaló antes, a través de la interpretación expansiva, armónica, evolutiva e interdependiente de distintos derechos reconocidos en la $\mathrm{CADH}$ y en otros instrumentos internacionales ${ }^{53}$.

En otros ejercicios similares, la Corte IDH ha sostenido que las personas tienen un derecho e, incluso, un deber de defender la democracia en el contexto de un rompimiento de un régimen de normalidad institucional. Este criterio, establecido en la sentencia de fondo del caso López Lone y otros contra Honduras, deriva de la interpretación expansiva e interdependiente del derecho a participar en los asuntos políticos de una sociedad, la libertad de expresión, de asociación y de reunión ${ }^{54}$.

\footnotetext{
51 Ibídem, párr. 138.

52 Corte Interamericana de Derechos Humanos. Artavia Murillo y otros (Fecundación in vitro) Vs. Costa Rica (2012), párr. 272.

53 En la sentencia de fondo del caso Artavia Murillo y otros, la corte analizó la vinculación directa entre los derechos a la vida privada y libertad reproductiva, junto con el derecho a beneficiarse del progreso científico, reconocido en los artículos 15.b del Pacto Internacional de Derechos Económicos, Sociales y Culturales y XIII de la Declaración Americana de Derechos y Deberes del Hombre, así como en algunos otros instrumentos internacionales específicos, tales como la Declaración sobre la Utilización del Progreso Científico y Tecnológico en Interés de la Paz y en Beneficio de la Humanidad. Ibídem, párr. 150.

54 Corte Interamericana de Derechos Humanos. López Lone y otros Vs. Honduras (2015), párr. 164.
} 


\subsection{Interpretación amplia de las obligaciones estatales}

Según se apuntó al inicio de esta sección, como complemento necesario de la interpretación expansiva de derechos, la Corte IDH ha prestado particular atención a los argumentos que desarrollan el alcance de las obligaciones estatales. Desde la doctrina interamericana, de poco serviría alegar el derecho de una persona a una protección especial considerando, por ejemplo, su situación particular en un contexto de vulnerabilidad, si no se pueden identificar las obligaciones estatales correspondientes. La interpretación amplia de las obligaciones se vincula, más aun, con la regla general de la exigibilidad de los derechos humanos, según la propuesta inicial del juez Piza Escalante respecto a la operación del principio pro persona.

Uno de los primeros ejercicios de esta interpretación amplia de las obligaciones estatales se propuso en relación con el derecho a la vida. En el caso Villagrán Morales y otros contra Guatemala, la Corte IDH afirmó la relevancia de las obligaciones positivas del Estado respecto a un derecho que, en términos textuales del artículo 4.1 de la $\mathrm{CADH}$, proscribía solo la privación arbitraria de la vida. En este sentido, la Corte IDH afirmó que este derecho no admite enfoques restrictivos, por lo que los Estados tienen la obligación de no impedir "el acceso a las condiciones que le garanticen una existencia digna[,] [así como] de garantizar la creación de las condiciones que se requieran para que no se produzcan violaciones de ese derecho básico [...]"55. En el mismo sentido, la Corte IDH afirmó, en el caso Comunidad Indigena Sawhoyamaxa contra Paraguay, que "los Estados tienen la obligación de garantizar la creación de las condiciones que se requieran para que no se produzcan violaciones de ese derecho inalienable" 56 . Los hechos relevantes de este asunto se centraban en las condiciones de vida de los miembros de la Comunidad Sawhoyamaxa del Pueblo Enxet-Lengua, caracterizadas por un "estado de vulnerabilidad alimenticia, médica y sanitaria, que amenaza[ba] en forma continua su supervivencia e integridad" 57 . Dicho estado de vulnerabilidad se originó por la falta de titulación y acceso al territorio tradicional de la comunidad ${ }^{58}$.

55 Corte Interamericana de Derechos Humanos. "Niños de la Calle" (Villagrán Morales y otros) vs. Guatemala (2001), párr. 144.

56 Corte Interamericana de Derechos Humanos. Comunidad Indigena Sawhoyamaxa vs. Paraguay (2006), párr. 151.

57 Ibídem, párr. 2.

58 Ibídem. 
En la misma línea de las decisiones arriba referidas, en el caso Vereda La Esperanza contra Colombia, la Corte IDH afirmó que "los Estados deben tomar en cuenta que los grupos de personas que viven en circunstancias adversas y con menos recursos, tales como las personas en condiciones de pobreza, enfrentan un incremento en el grado de afectación a sus derechos precisamente por su situación de mayor vulnerabilidad"59. En consecuencia, la Corte IDH reconoció la afectación diferenciada o desproporcionada que la conducta estatal produce en ciertos grupos, lo cual deriva a su vez en la calificación jurídica de los hechos como violaciones graves a los derechos humanos ${ }^{60}$. Con estas bases, se afirmó también la necesidad de adoptar una visión reforzada sobre las obligaciones estatales, incluso en relación con derechos como la propiedad privada ${ }^{61}$, tradicionalmente identificado con un discurso liberal o burgués de los derechos.

De manera paralela a los contextos de vulnerabilidad económica, la Corte IDH también ha recurrido a una interpretación amplia de las obligaciones estatales para establecer marcos más precisos de tutela para personas que, a pesar de situarse en una posición particular respecto al ejercicio del poder público, no tienen una protección especial en la CADH. Por ejemplo, en el caso Ximenes Lopes contra Brasil, la Corte IDH desarrolló a detalle el alcance de las obligaciones estatales frente a los derechos a la vida e integridad de las personas que padecen algún tipo de enfermedad o deficiencia mental ${ }^{62}$. Como en otras decisiones, la Corte IDH no hizo referencia expresa al principio pro persona o, incluso, al artículo 29 de la CADH. Sin embargo, la argumentación de la Corte IDH indudablemente conduce a una protección más expansiva de los derechos de un grupo específico de personas que no tienen un reconocimiento especial en la $\mathrm{CADH}$.

Esta misma estrategia fue fundamental en el caso Quispialaya Vilcapoma contra Perú. En la sentencia de fondo respectiva, la Corte IDH sostuvo la posición de garante del Estado frente a personas en custodia o "en especial relación de sujeción"63. En el caso concreto, la víctima era un cadete militar que fue objeto

\footnotetext{
59 Corte Interamericana de Derechos Humanos. Vereda La Esperanza vs. Colombia (2017), párr. 240.

60 Ibídem, párr. 241.

61 Ibídem.

62 Corte Interamericana de Derechos Humanos. Ximenes Lopes Vs. Brasil (2006), párrs. 137-148.

63 Corte Interamericana de Derechos Humanos. Quispialaya Vilcapoma Vs. Perú (2015), párrs. 115 y ss. De forma precisa, la Corte IDH sostuvo que "[l] a situación diferenciada bajo la cual se presta el servicio militar [acuartelado] conlleva una restricción o limitación a los derechos y libertades de los reclutas, generando con ello no propiamente una privación de libertad, pero una situación en la que el Estado es el garante y
} 
de actos de violencia física, perpetrados por sus superiores durante un ejercicio de prácticas militares de tiro ${ }^{64}$. A pesar de haber ingresado a la institución castrense de forma voluntaria, la Corte IDH concluyó que al momento de los hechos violatorios, la persona no tenía plena autonomía o libertad para abandonar las instalaciones militares, situación que originó la mencionada relación de sujeción.

$\mathrm{Al}$ igual que la interpretación del contenido de los derechos, en distintos casos la construcción amplia de las obligaciones ha estado vinculada con una visión evolutiva de las mismas. En la sentencia de fondo del caso Vélez Loor contra Panamá, la Corte IDH advirtió tanto la vulnerabilidad social como cultural que sufren las personas migrantes, al tiempo que sustentó la existencia de una serie de obligaciones estatales especiales en la materia, a través de un argumento centrado en la evolución del corpus iure internacional de protección a los derechos de las personas migrantes ${ }^{65}$. En este sentido, la Corte IDH concluyó que "la evolución de este ámbito del derecho internacional ha desarrollado ciertos límites a la aplicación de las políticas migratorias que imponen un apego estricto a las garantías del debido proceso y al respeto de la dignidad humana [nota omitida], cualquiera que sea la condición jurídica del migrante" 66 . La relevancia de este criterio no puede ser minimizada, considerando que los asuntos migratorios han sido uno de los bastiones más difíciles de penetrar, por lo que se refiere a la discrecionalidad estatal para el diseño e implementación de marcos normativos o políticas públicas relacionadas con temas de desarrollo nacional.

De la misma forma, la Corte IDH ha destacado el impacto que la interpretación expansiva e interdependiente de los derechos tiene en las obligaciones estatales. En el caso I.V. contra Bolivia se sostuvo, por ejemplo, que

la existencia de una conexión entre la integridad fisica y psicológica con la autonomía personal y la libertad de tomar decisiones sobre el propio cuerpo y la salud exige, por un lado, que el Estado asegure y respete decisiones y elecciones hechas de forma libre y responsable y, por el otro, que se garantice el acceso a la información relevante para que

custodio de los individuos sometidos a ese régimen [...]. [L]a Corte concluye que [una persona en servicio militar activo acuartelado] se encuentra frente a una especial situación de sujeción, que a su vez impone al Estado una posición de garante. Desde esa perspectiva, se encuentra en una situación similar a las personas privadas de libertad, y por lo tanto resultan aplicables los estándares establecidos en su jurisprudencia en relación a estas personas". Ibídem, párrs. 119 y 123.

64 Ibídem, párrs. 60-63.

65 Corte Interamericana de Derechos Humanos. Vélez Loor Vs. Panamá (2010), párrs. 98-99.

66 Ibídem, párr. 100. 
las personas estén en condiciones de tomar decisiones informadas sobre el curso de acción respecto a su cuerpo y salud de acuerdo a su propio plan de existencia ${ }^{67}$.

Estos casos enfatizan la correlación entre la interpretación de los derechos y las obligaciones estatales. Lo anterior no significa, sin embargo, que la Corte IDH no reconozca ciertos límites al alcance de estas. A pesar de afirmar que las obligaciones en materia de derechos humanos tienen un carácter erga omnes, el tribunal interamericano también ha afirmado que no se puede considerar al Estado responsable por cualquier situación que ponga en riesgo los derechos de las personas. En este sentido, se han delineado algunos criterios de "control", como la necesidad de establecer que las autoridades estatales conocían o debían haber conocido del riesgo de violación a los derechos, atendiendo a las circunstancias o contextos específicos de cada caso ${ }^{68}$. Estos criterios no deben confundirse con una interpretación limitada de las obligaciones estatales, sino que constituyen estrategias argumentativas que buscan habilitar ciertos márgenes de discrecionalidad o "apreciación” para el diseño e implementación de políticas públicas en materia de derechos humanos, al tiempo que establecen estándares realistas respecto a la posible determinación de responsabilidad estatal. Tal como ha señalado la Corte IDH, sujetar a los Estados a obligaciones desproporcionadas o de imposible cumplimento tampoco redundaría en la protección efectiva de los derechos.

\subsection{Interpretación limitada de las restricciones a los derechos humanos}

La tercera dimensión de la interpretación pro persona en la jurisprudencia de la Corte IDH corresponde, como se apuntó al inicio de esta sección, al análisis

67 Corte Interamericana de Derechos Humanos. I.V, Vs. Bolivia (2016), párr. 115.

68 En el caso de la Comunidad Indígena Sawhoyamaxa contra Paraguay, la Corte IDH concluyó que "un Estado no puede ser responsable por cualquier situación de riesgo al derecho a la vida. Teniendo en cuenta las dificultades que implica la planificación y adopción de políticas públicas y las elecciones de carácter operativo que deben ser tomadas en función de prioridades y recursos, las obligaciones positivas del Estado deben interpretarse de forma que no se imponga a las autoridades una carga imposible o desproporcionada [nota omitida]. Para que surja esta obligación positiva, debe establecerse que al momento de los hechos las autoridades sabían o debían saber de la existencia de una situación de riesgo real e inmediato para la vida de un individuo o grupo de individuos determinados, y no tomaron las medidas necesarias dentro del ámbito de sus atribuciones que, juzgadas razonablemente, podían esperarse para prevenir o evitar ese riesgo". Corte Interamericana de Derechos Humanos. Comunidad Indigena Sawhoyamaxa Vs. Paraguay (2006), párr. 155. En la misma línea, véase, por ejemplo, Corte Interamericana de Derechos Humanos. Suárez Peralta Vs. Ecuador (2013), párr. 129. 
limitativo de las restricciones (ordinarias) al ejercicio de los derechos ${ }^{69}$. Esta afirmación se basa en dos premisas esenciales. En primer lugar, destaca el reconocimiento de que el ejercicio de los derechos humanos no es nunca absoluto, por lo que el mismo siempre es limitable atendiendo al contexto concreto. No obstante lo anterior, dada la presunción de primacía de los derechos humanos frente al ejercicio del poder público, esas limitaciones deben construirse, normativamente, como una excepción a la regla. De forma explícita, la Corte IDH ha sostenido que "la facultad de los Estados de regular o restringir estos derechos no es discrecional y cualquier limitación a los derechos consagrados en la Convención debe interpretarse de manera restrictiva"70.

El sustento jurídico de esta línea de argumentación es, precisamente, el artículo 29 de la CADH. Es importante notar que, en la práctica, el tema de las restricciones ordinarias al ejercicio de los derechos humanos es un aspecto de análisis relativamente reciente dentro de la jurisprudencia de la Corte IDH. Atendiendo al contexto sociopolítico que marcó las primeras décadas de operación de la propia Corte IDH -caracterizado por conflictos armados o regímenes dictatoriales en los que se cometían violaciones graves a los derechos humanos a gran escala-, es natural que una evaluación jurídica más fina sobre los límites ordinarios al ejercicio de los derechos correspondiera a una etapa posterior del desarrollo de las democracias latinoamericanas y, por ende, de la propia jurisprudencia interamericana.

En términos más concretos, la primera vez que la Corte IDH se pronunció sobre la imposibilidad de ampliar las restricciones contenidas en la $\mathrm{CADH}$ fue en el contexto de la Opinión Consultiva 5/85. Esta opinión fue el resultado de una solicitud presentada por el gobierno de Costa Rica, respecto a la compatibilidad del proyecto de Ley Orgánica del Colegio de Periodistas de Costa Rica con el derecho a la libertad de expresión, reconocido en el artículo 13 de la $\mathrm{CADH}$. En ocasión de esta decisión, la Corte IDH puntualizó que "frecuentemente es útil [...] comparar la Convención Americana con lo dispuesto en otros instrumentos internacionales como medio para poner de relieve aspectos particulares de la

69 Para fines de una claridad conceptual, es importante señalar que en la jurisprudencia de la Corte IDH el término "restricciones" se utiliza de forma análoga al concepto de "límites" y en contraste con la noción de la suspensión de derechos humanos en estados de excepción. Sobre el particular, véase, por ejemplo, Corte Interamericana de Derechos Humanos. La expresión "Leyes" en el artículo 30 de la Convención Americana sobre Derechos Humanos. (1986); Corte Interamericana de Derechos Humanos. El hábeas corpus bajo suspensión de garantías (1987); Corte Interamericana de Derechos Humanos. Garantías judiciales en estados de emergencia (1987).

70 Corte Interamericana de Derechos Humanos. Ruano Torres y otros Vs. El Salvador (2015), párr. 172. 
regulación de un determinado derecho[.] [Sin embargo] tal método no podría emplearse nunca para incorporar a la Convención criterios restrictivos que no se desprendan directamente de su texto, por más que estén presentes en cualquier otro tratado internacional"71. Esta conclusión se sustentó en el artículo 29.b de la propia CADH, el cual prohíbe "limitar el goce y ejercicio de cualquier derecho o libertad que pueda estar reconocido d leyes de cualquiera de los Estados Partes o de acuerdo con otra convención en que sea parte uno de dichos Estados". Dada la importancia que esta opinión reviste para el debate sobre la selección de la norma más favorable, la misma será analizada con mayor profundidad en la siguiente sección de este mismo artículo.

En años más recientes, el principio pro persona ha sido utilizado, por ejemplo, en el marco de las discusiones sobre el alcance del fuero militar a la luz de los derechos al debido proceso y al acceso a la justicia de las víctimas de violaciones a los derechos humanos. Sobre este tema, la Corte IDH ha reiterado que, en una sociedad democrática, la justicia castrense solo puede entenderse como una excepción a la jurisdicción natural de los tribunales ordinarios, por lo que "ha de tener un alcance restrictivo y excepcional y estar encaminada a la protección de intereses jurídicos especiales, vinculados con las funciones que la ley asigna a las fuerzas militares"72. Por lo tanto, continúa afirmando la Corte IDH, "sólo se debe juzgar a militares por la comisión de delitos o faltas que por su propia naturaleza atenten contra bienes jurídicos propios del orden militar"73. Al respecto, la Corte IDH ha afirmado que para determinar si un hecho está directamente relacionado con el servicio se debe recurrir, en aplicación del principio pro persona, a la interpretación más restrictiva posible. Así, por ejemplo, en el caso 19 Comerciantes contra Colombia, la Corte IDH afirmó que "[n]o hay lugar a dudas de que la participación que pudieran haber tenido los militares investigados al 'conoc[er] de las actividades delictivas de grupos al margen de la [1]ey, [...] prest[ándoles] apoyo y cohonesta[ndo] los acontecimientos delictivos' [...] de la detención, la desaparición y la muerte de los 19 comerciantes, así como en la sustracción de

\footnotetext{
71 Corte Interamericana de Derechos Humanos. La colegiación obligatoria de periodistas (1985), párr. 51.

72 Corte Interamericana de Derechos Humanos. Radilla Pacheco vs. México (2009), párr. 209; Corte Interamericana de Derechos Humanos. Fernández Ortega y otros vs. México (2010), párr. 176; Corte Interamericana de Derechos Humanos. Rosendo Cantú y otra vs. México (2010), párr. 160; Corte Interamericana de Derechos Humanos. Cabrera García y Montiel Flores Vs. México (2010), párr. 197.

73 Ibídem. Véase, también, Corte Interamericana de Derechos Humanos. Las Palmeras vs. Colombia (2001), párr. 51.
} 
sus vehículos y mercancías, no tiene una relación directa con un servicio o tarea militar" 74 . En consecuencia, los procesos ante autoridades del fuero militar resultaban en una restricción contraria al reconocimiento convencional de los derechos al debido proceso y acceso a la justicia de las víctimas.

En otro caso, también relacionado con los posibles límites de las garantías procesales (ahora en materia penal), la Corte IDH sostuvo que de conformidad con el derecho a la inviolabilidad del domicilio, reconocido en el artículo 11.2 de la $\mathrm{CADH}$, "la obtención de la debida autorización o de una orden judicial para realizar un registro o allanamiento domiciliario debe ser entendida como la regla general y sus excepciones, tales como la flagrancia, son válidas sólo en las circunstancias establecidas en la ley, las cuales, precisamente en tanto excepciones, deben ser estrictamente interpretadas" 75 .

La Corte IDH utilizó una aproximación similar en el caso López Lone contra Honduras. Los hechos del mismo se referían a los procedimientos disciplinarios seguidos en contra de cuatro miembros del poder judicial nacional, por sus posiciones públicas en contra del rompimiento del régimen democrático ocurrido en Honduras en 2007. Al analizar el alcance de los derechos políticos de los jueces, la Corte IDH determinó que "[1]a restricción de participación en actividades de tipo partidista a los jueces no debe ser interpretada de manera amplia, de forma tal que impida que los jueces participen en cualquier discusión de índole política" 76 . Esta afirmación fue la puerta de entrada para que la propia Corte IDH avanzara el argumento central de su decisión: en ciertas situaciones excepcionales, como el rompimiento ilegítimo de un régimen democrático, los jueces tienen del derecho (incluso el deber) de expresarse y participar activamente en las decisiones políticas. Consecuentemente, la interpretación limitada de una restricción ordinaria al ejercicio de un derecho se convierte también en la base para sostener la falta de justificación convencional para otra restricción, en determinadas circunstancias.

Un ejemplo aún más complejo del debate sobre la interpretación limitativa de las restricciones se planteó ante la Corte IDH en distintos casos relacionados con condenas nacionales a pena de muerte. Como es ampliamente conocido, la $\mathrm{CADH}$ no contiene una prohibición absoluta de esta pena, sino que limita su imposición a "los delitos más graves, en cumplimiento de sentencia ejecutoriada de tribunal

74 Corte Interamericana de Derechos Humanos. 19 Comerciantes vs. Colombia (2004), párr. 164.

75 Corte Interamericana de Derechos Humanos. Pollo Rivera y otros Vs. Perú (2016), párr. 116.

76 Corte Interamericana de Derechos Humanos. Ruano Torres y otros Vs. El Salvador (2015), párr. 172. 
competente y de conformidad con una ley que establezca tal pena, dictada con anterioridad a la comisión del delito" 77 . El único instrumento interamericano que prohíbe, de forma absoluta, la imposición de la pena de muerte es el Protocolo a la Convención Americana sobre Derechos Humanos relativo a la Abolición de la Pena de Muerte. En este contexto, si bien el protocolo mencionado contiene una disposición más protectora que la $\mathrm{CADH}$, la Corte IDH ha considerado que está imposibilitada para aplicar dicho protocolo en casos contra Estados que no sean parte del mismo. No obstante el claro límite normativo para la selección de las disposiciones más favorables, la Corte IDH ha podido interpretar, en aplicación del principio pro persona, las normas que regulan la imposición de la pena de muerte de la manera más restrictiva posible. El argumento avanzado por la Corte IDH corre en la siguiente línea:

la Corte ha observado que el artículo 4.2 de [la CADH] permite la privación del derecho a la vida mediante la imposición de la pena de muerte en aquellos paises en los cuales no está abolida. Es decir, la pena capital no es per se incompatible con la Convención Americana ni está prohibida por ella. Sin embargo, la Convención fija un número de limitaciones estrictas para la aplicación de la pena capital [...]. En especial, al abordar el tema de la aplicación de la pena capital en otros casos, la Corte ha sostenido que las referencias a los términos "arbitrariamente" en el artículo 4.1 de la Convención y a "los delitos más graves" en el artículo 4.2 tornan incompatible la imposición obligatoria de la pena capital con aquellas disposiciones en tanto la misma pena se aplica a conductas que pueden variar considerablemente y cuando no se restringe su aplicación a los delitos más graves [nota omitida] [...]. Las disposiciones de la Convención respecto de la aplicación de la pena de muerte deben interpretarse [...] conforme al principio pro persona, es decir, a favor del individuo [nota omitida], en el sentido de "limitar definitivamente su aplicación y su ámbito, de modo que ést[a] se vaya reduciendo hasta su supresión final" [nota omitida] [...]. [Así, con base en la interpretación más favorable, es posible afirmar que] el Estado incorrectamente asume que una pena de muerte legalmente impuesta no podría ser también arbitraria. Una pena de muerte obligatoria legalmente impuesta puede ser arbitraria cuando la ley no distingue entre los distintos grados de culpabilidad del acusado ni toma en consideración las circunstancias particulares de cada delito ${ }^{78}$.

Los párrafos arriba transcritos deben ser leídos con cuidado. Sin recurrir a la norma internacional más favorable (con base en un límite jurídico insalvable), la Corte IDH logra argumentar en favor de la protección más amplia de los dere-

77 Convención Americana sobre Derechos Humanos (1969), artículo 4.2.

78 Corte Interamericana de Derechos Humanos. Boyce y otros Vs. Barbados (2007), párrs. 50-52 y 57. 
chos de las personas, al analizar las disposiciones nacionales a la luz de la lectura más restringida posible de normas internacionales que, de inicio, restringen el goce del derecho a la vida al permitir la imposición legal de la pena de muerte. Esta es, precisamente, la interpretación restrictiva que resulta del uso correcto del principio pro persona.

Estos ejemplos no tienen ninguna aspiración de exhaustividad respecto a un tema tan amplio y complejo como las restricciones constitucionales o legales a los derechos humanos. Su objetivo es solamente demostrar que, antes que el debate sobre la selección normativa, la Corte IDH ha afirmado la importancia de interpretar limitativamente cualquier disposición jurídica (convencional, constitucional o legal) que pueda contener un límite al ejercicio ordinario de un derecho. En otras palabras, para la Corte IDH, las restricciones establecidas por una ley en sentido formal y material ${ }^{79}$ no son cláusulas de aplicación inmediata, sino que deben interpretarse siempre de forma restrictiva, a fin de cumplir con el mandato general de exigibilidad de los derechos que impone el principio pro persona.

\section{LA APLICACIÓN DE LA NORMA MÁS FAVORABLE EN LA JURISPRUDENCIA DE LA Corte InTeramericana de Derechos Humanos}

De la mano con el análisis de la interpretación expansiva de los derechos humanos y las obligaciones estatales, el principio pro persona ha detonado también un debate respecto al "principio de aplicación de la norma más favorable". Como se señaló al inicio del análisis, este criterio ha sido entendido por parte de la académica latinoamericana como una de las vertientes del principio propersona. Según dichas propuestas dogmáticas, esta vertiente normativa se entiende como un nuevo criterio de solución de antinomias normativas, junto con los principios de jerarquía, temporalidad o especialidad. Más aún, en algunos órdenes constitucionales, como el mexicano, el mandato expreso del principio pro persona debería incluso llevar a desplazar la preferencia tradicional por los otros criterios antes mencionados, a fin de privilegiar siempre la aplicación de la norma más favorable en los casos concretos.

Dadas las repercusiones que esta afirmación tendría en nuestros sistemas jurídicos, en esta sección se propone un examen más puntual sobre las decisiones de la Corte IDH en que se ha hecho referencia explícita al "principio de aplicación

79 Corte Interamericana de Derechos Humanos. La expresión "Leyes" en el artículo 30 de la Convención Americana sobre Derechos Humanos (1986), párrs. 17-18. 
de la norma más favorable". La finalidad de este análisis es aportar nuevas luces a un debate que ha tenido implicaciones importantes en la construcción jurisdiccional de los derechos humanos en sede nacional, al menos en el marco de la práctica jurídica mexicana.

Como consideraciones previas al estudio de las resoluciones interamericanas, es oportuno distinguir al menos tres escenarios en que teóricamente podría presentarse una contradicción normativa, en el contexto de un caso ante la Corte IDH. En primer lugar, dicha contradicción podría existir cuando dos o más disposiciones jurídicas, establecidas en distintas fuentes internacionales, reconozcan estándares diferenciados de protección aplicables en el mismo supuesto. En segundo lugar, la contradicción podría plantearse entre una disposición internacional, por un lado, y una disposición constitucional, por el otro. En tercer lugar, la discrepancia se podría presentar entre una disposición convencional o constitucional frente a una norma secundaria nacional. Las decisiones que se analizan en esta sección abarcan casos en que la Corte IDH ha tenido que pronunciarse sobre cada uno de estos escenarios, por lo que sirven para construir un criterio suficientemente integral.

En orden meramente cronológico, la primera vez que el tribunal interamericano hizo referencia al "principio de la aplicación de la norma más favorable" fue el en marco de la Opinión Consultiva 5/8580. Según se destacó antes, esta opinión fue solicitada por el Estado de Costa Rica, a fin de determinar la compatibilidad del proyecto de la Ley Orgánica del Colegio de Periodistas de Costa Rica con el marco internacional de derechos humanos. Materialmente, el parámetro de análisis para la opinión de la Corte IDH era, entonces, el artículo 13 de la CADH, en el cual se reconoce el derecho a la libertad de expresión.

Como parte de sus argumentos, Costa Rica sostuvo que cuando la $\mathrm{CADH}$ reconoce un derecho de forma más amplia que otros tratados internacionales, la legislación nacional solo tendría que sujetarse a la norma menos gravosa para la actuación estatal. De otra forma, "tendríamos que aceptar que lo que es lícito y permisible en el ámbito universal, constituiría una violación en el continente americano, lo que parece evidentemente una afirmación errónea [...]. Más bien pensamos que en cuanto a interpretación de tratados, puede sentarse el criterio de

80 En dicha decisión, la Corte IDH afirmó que "si a una misma situación son aplicables la Convención Americana y otro tratado internacional, debe prevalecer la norma más favorable a la persona humana. Si la propia Convención establece que sus regulaciones no tienen efecto restrictivo sobre otros instrumentos internacionales, menos aún podrán traerse restricciones presentes en esos otros instrumentos, pero no en la Convención, para limitar el ejercicio de los derechos y libertades que ésta reconoce". Corte Interamericana de Derechos Humanos. La colegiación obligatoria de periodistas (1985), párr. 52. 
que las reglas de un tratado o convención deben interpretarse en relación con las disposiciones que aparezcan en otros tratados que versen sobre la misma materia" 81 .

Como se señaló en la sección anterior, este argumento fue finalmente desechado por la Corte IDH. En la opinión de este tribunal, el proceso de creación de normas internas necesariamente implica que los Estados se sujeten a los estándares internacionales más protectores para los derechos humanos, aun cuando otros acuerdos, convenios o tratados internacionales de los que sean parte permitan imponer restricciones adicionales al ejercicio de los derechos ${ }^{82}$

Con esta opinión consultiva, la Corte IDH estableció dos criterios fundamentales para la labor legislativa de implementación en derechos humanos. En primer lugar, se sostiene la presunción a favor del ejercicio y exigibilidad de los derechos, aun si esto implica una opción más gravosa para la actuación estatal. En segundo lugar, implícitamente la Corte IDH reconoce que, frente a la fragmentación del DIP o del propio DIDH, los Estados tienen la obligación de armonizar o adecuar su propia legislación interna, con base en la selección de los estándares más altos de protección para los derechos.

Este es un ejemplo, entonces, de una posible discrepancia entre normas internacionales que contienen distintos estándares de protección. La "selección" de la norma más favorable no tiene, sin embargo, un efecto directo en la argumentación judicial (nacional o internacional), sino en la labor legislativa de implementación de tratados internacionales. Lo anterior, en línea con la pauta regulatoria propuesta en su momento por Mónica Pinto, en contraste con la vertiente normativa que se ha atribuido al principio pro persona.

En ocasiones subsecuentes, la Corte IDH se pronunció nuevamente sobre el "principio de aplicación de la norma más favorable", al analizar la interrelación de normas internacionales. Por ejemplo, en el caso Masacre de Mapiripán contra Colombia, el tribunal interamericano hizo referencia expresa a la aplicación de la norma más favorable, como parte del examen de los criterios internacionales que rigen la responsabilidad de los Estados en materia de derechos humanos. Ahora

81 Ibídem, párr. 51.

82 Es oportuno recordar que fue precisamente en el marco de la Opinión Consultiva 5/85 en que el juez Rodolfo Piza Escalante articuló lo que parece ser la primera definición del principio pro persona (antes conocido como principio pro homine). Corte Interamericana de Derechos Humanos. La Colegiación Obligatoria de Periodistas (1985). Opinión separada del juez Rodolfo E. Piza Escalante, párr. 12. Véase, también, Corte Interamericana de Derechos Humanos. Exigibilidad del derecho de rectificación o respuesta (1986). Opinión separada del juez Rodolfo E. Piza Escalante, párr. 36. 
bien, según apuntó la propia Corte IDH más adelante en el fallo, el análisis en cuestión trata de la aplicación de la lex specialis internacional frente el régimen general de DIP que regula la responsabilidad de los Estados por hechos ilícitos ${ }^{83}$. Como se examinó previamente en este mismo artículo, este es un debate clásico de la relación de los regímenes autocontenidos vis-à-vis el derecho internacional público general, que difícilmente puede asimilarse con la solución de antinomias jurídicas como tradicionalmente se entienden en los sistemas jurídicos nacionales codificados.

Por su parte, en el caso Herrera Ulloa contra Costa Rica el principio pro persona (en referencia a la norma más favorable) se utilizó con el propósito de determinar los efectos vinculantes de las decisiones de la Comisión Interamericana de Derechos Humanos. Esta posición tiene un impacto directo en la eficacia de los órganos de protección del SIDH, pero tampoco es relevante para el debate sobre la solución de una antinomia normativa ${ }^{84}$.

El término de la "aplicación de la norma más favorable" volvió a ser utilizado, en un contexto distinto, en el caso Ricardo Canese contra Paraguay. Este asunto trataba, entre otros temas, sobre las violaciones derivadas de la inobservancia de los principios de legalidad y de retroactividad, consagrados en el artículo $9^{\circ}$ de la $\mathrm{CADH}$. En este fallo, la Corte IDH efectivamente afirmó que, si en una situación son aplicables dos o más disposiciones normativas, se debe recurrir a aquella que más proteja a la persona ${ }^{85}$. No obstante, es fundamental tener cuenta que este caso se refiriere a la aplicación retroactiva de una ley penal nacional más benéfica, que implica en sí mismo un principio de favorabilidad o trato más favorable, reconocido por una multiplicidad de sistemas jurídicos. Poco o nada tiene que ver este caso con la posibilidad de utilizar el principio pro persona como un cri-

83 Corte Interamericana de Derechos Humanos. Masacre de Mapiripán Vs. Colombia (2005), párrs. 104-107.

84 El texto concreto del fallo en cuestión lee de la siguiente manera: "El artículo 50 de la Convención se refiere a la emisión, por parte de la Comisión, de un informe que se le transmite al Estado, con carácter reservado, para que cumpla una serie de recomendaciones y solucione el asunto. Si dentro de los tres meses siguientes a la remisión del informe al Estado, el asunto no se ha solucionado y la Comisión considera que aquél no cumplió, ésta tendrá dos opciones: enviar el caso a la Corte mediante la interposición de la demanda o emitir el informe del artículo 51 de la Convención, el cual, mediante votación de mayoría absoluta de sus miembros, contendrá su opinión y conclusiones sobre la cuestión sometida a su consideración [...]. La Corte ya ha dicho que esta decisión no es discrecional, sino que 'debe apoyarse en la alternativa que sea más favorable para la tutela de los derechos humanos' establecidos en la Convención”. Corte Interamericana de Derechos Humanos. Herrera Ulloa vs. Costa Rica (2004), párr. 184.

85 Corte Interamericana de Derechos Humanos. Ricardo Canese vs. Paraguay (2004), párrs. 178-181. 
terio de solución de antinomias jurídicas, aun cuando la propia sentencia haga referencia al "principio de aplicación de la norma más favorable" 86 . Lo anterior resalta, nuevamente, la importancia de analizar de forma detallada los argumentos jurídicos de la Corte IDH antes de proponer una conclusión sobre el sentido de los términos utilizados por la misma.

En el contexto de un debate similar, la sentencia de fondo del caso Baena Ricardo contra Panamá parece ser un ejemplo más concreto de una construcción normativa del derecho a la legalidad penal que, efectivamente, deriva en la aplicación (por analogía) de una norma más favorable. Al discutir si "el artículo 9o de la Convención es aplicable a la materia sancionatoria administrativa”, la Corte IDH concluyó que

[l]os términos utilizados en dicho precepto parecen referirse exclusivamente a [la materia sancionadora penall. Sin embargo, es preciso tomar en cuenta que las sanciones administrativas son, como las penales, una expresión del poder punitivo del Estado y que tienen, en ocasiones, naturaleza similar a la de éstas. Unas y otras implican menoscabo, privación o alteración de los derechos de las personas, como consecuencia de una conducta ilícita. Por lo tanto, en un sistema democrático es preciso extremar las precauciones para que dichas medidas se adopten con estricto respeto a los derechos básicos de las personas y previa una cuidadosa verificación de la efectiva existencia de la conducta ilícita. Asimismo, en aras de la seguridad jurídica es indispensable que la norma punitiva, sea penal o administrativa, exista y resulte conocida, o pueda serlo, antes de que ocurran la acción o la omisión que la contravienen y que se pretende sancionar. La calificación de un hecho como ilícito y la fijación de sus efectos jurídicos deben ser preexistentes a la conducta del sujeto al que se considera infractor. De lo contrario, los particulares no podrian orientar su comportamiento conforme a un orden jurídico vigente y cierto, en el que se expresan el reproche social y las consecuencias de este. Estos son los fundamentos de los principios de legalidad y de irretroactividad desfavorable de una norma punitiva ${ }^{87}$.

Si bien el efecto de la decisión de la Corte IDH es, de hecho, la aplicación (por analogía) de normas más favorables, el fundamento de su argumento no es la solución de una antinomia normativa, sino la interpretación expansiva de

86 De manera paralela a la discusión central de este artículo, es oportuno hacer notar que la sentencia en el caso Ricardo Canese contra Paraguay es un ejemplo de los problemas que pueden suscitarse cuando el principio pro persona se asimila, de forma automática, a cualquier otro principio de favorabilidad o favorecimiento. Sobre este punto, es importante recordar que en tanto que este tipo de principios tienden a operar en relación con derechos específicos o situaciones concretas (pro actione, pro reo, pro víctima, pro operario), el principio pro persona es un criterio que debe permear todas las normas de derechos humanos, sin limitarse a proporcionar criterios previamente determinados para ciertos contextos.

87 Corte Interamericana de Derechos Humanos. Baena Ricardo y otros vs. Panamá (2001), párr. 106. 
un derecho reconocido en la $\mathrm{CADH}$ (principio de legalidad, artículo $9^{\circ}$ de la $\mathrm{CADH})$. Desde una lectura detallada de la sentencia, es posible concluir que la misma tampoco parece servir como fundamento jurisprudencial para afirmar la vertiente normativa del principio pro persona, tal como ha sido propuesta por la doctrina latinoamericana. Por el contrario, la sentencia en el caso Baena, Ricardo contra Panamá parece reforzar la utilidad de realizar un ejercicio preciso de interpretación expansiva del contenido de los derechos y, al mismo tiempo, limitada de sus restricciones.

Evidentemente, existen muchos casos en que la Corte IDH ha determinado la incompatibilidad de una norma nacional secundaria con los derechos reconocidos por la CADH. Dichos criterios corresponden, sin embargo, a una función clásica de evaluación del cumplimiento de las obligaciones internacionales en materia de derechos humanos -en particular, la obligación de adoptar medidas legislativas o de otra índole-, lo que tampoco implica un ejercicio de selección normativa de conformidad con la propuesta del principio pro persona. En todo caso, la "selección" implicaría solo determinar el parámetro normativo de control convencional de la norma nacional, el cual de cualquier forma implicaría una interpretación expansiva de los derechos relevantes, según la práctica antes examinada.

En contraste con la claridad que implica el debate sobre las normas nacionales secundarias, el análisis de la contradicción entre una disposición constitucional y una convencional puede plantear un escenario mucho más complejo. Tal como se apuntó al inicio de esta sección, este es el tercer y último supuesto en que la vertiente normativa del concepto pro persona podría tener una función esencial en la jurisprudencia latinoamericana.

Probablemente el caso más reconocido dentro de este debate es "La Última Tentación de Cristo" (Olmedo Bustos y otros) vs. Chile. En la decisión de fondo correspondiente, la Corte IDH determinó que el artículo 19.12 de la Constitución Política de Chile de 1980 era incompatible con la CADH, al establecer un sistema de censura previa para la exhibición y publicidad de la producción cinematográfica. Dicha norma había sido utilizada por el Consejo de Calificación Cinematográfica para prohibir la proyección de la película "La última tentación de Cristo". En su oportunidad, la Corte Suprema de Justicia de Chile confirmó la decisión que negaba el permiso para exhibir la película ${ }^{88}$. En varios de los peritajes presentados

88 De conformidad con el fallo de la Corte IDH, parece que la Corte Suprema de Justicia de Chile realizó una especie de ejercicio de ponderación entre el derecho a la honra e intimidad, vinculado con la libertad de creencias, por un lado, y la libertad de expresión, por el otro. En cualquier caso, en el litigio ante la Corte 
se aludió al tema de la jerarquía de las normas constitucionales y convencionales en derechos humanos, así como a la importancia de que los tratados internacionales en la materia tuvieran eficacia normativa directa y primaria ante las cortes nacionales. Es decir, se resaltó la importancia de que las normas internacionales de derechos humanos fueran autoejecutables y pudieran ser invocadas directamente en juicio, sin la necesidad de contar con normas nacionales de implementación. En cualquier caso, la Corte IDH no requirió una acción específica por parte de las cortes nacionales, sino que centró su argumento en la necesidad de reformar la norma constitucional con base en la cual se desarrolló el sistema de censura previa. En palabras de la propia Corte IDH:

[e]n el derecho de gentes, una norma consuetudinaria prescribe que un Estado que ha ratificado un tratado de derechos humanos debe introducir en su derecho interno las modificaciones necesarias para asegurar el fiel cumplimiento de las obligaciones asumidas. Esta norma es universalmente aceptada, con respaldo jurisprudencial [nota omitida] [...]. [En este sentido][,] Chile debe adoptar las medidas apropiadas para reformar [...] su ordenamiento jurídico interno de manera acorde al respeto y el goce del derecho a la libertad de pensamiento y de expresión consagrado en la Convención ${ }^{89}$.

Este criterio establece una pauta indiscutiblemente importante para el estudio del principio pro persona. Frente a una contradicción expresa entre una norma constitucional y una norma convencional, la Corte IDH no requirió a las cortes nacionales la "selección" de la segunda, sino que ordenó la modificación de la primera; lo anterior, sujeto a los procedimientos establecidos en el derecho interno para tales fines. Si bien es cierto que este fallo precede el desarrollo formal de la doctrina del control de convencionalidad, nada en el argumento de la Corte IDH parece indicar que el sentido del fallo hubiera sido distinto, si la misma hubiera sido considerada como un aspecto estructural de la sentencia. En otras palabras, aun considerando la doctrina del control de convencionalidad, parece razonable presumir que la posición de la Corte IDH se centraría en la reforma de la norma constitucional, en contraste con su desaplicación en casos judiciales concretos.

En este mismo tenor, resulta interesante analizar, por último, el fallo de fondo en el caso Boyce y otros contra Barbados, un caso sobre la aplicación de la

IDH el Estado chileno reconoció que la sentencia de la Corte Suprema constituía una violación al derecho a la libertad de expresión.

89 Corte Interamericana de Derechos Humanos. "La Última Tentación de Cristo" (Olmedo Bustos y otros) vs. Chile (2001), párrs. 72 y 98. 
pena de muerte en el cual se presenta, nuevamente, un problema con una norma constitucional. De conformidad con el artículo $2^{\circ}$ de la Ley de Delitos contra las Personas de 1994 de Barbados (LDCP), a cualquier persona sentenciada por un homicidio se le aplicará, de forma automática, una condena a pena de muerte. La validez de dicha disposición normativa no podía ser impugnada ante los tribunales nacionales, ya que la sección 26 de la Constitución Política de Barbados prohibía a las cortes pronunciarse sobre la inconstitucionalidad de las leyes adoptadas con anterioridad a la entrada en vigor del propio texto constitucional (siendo este el caso de la LDCP $)^{90}$. En este contexto, la Corte IDH sostuvo que

[e]l análisis del [Comité Judicial del Consejo Privado (máximo tribunal de apelaciones de Barbados)] no debería haberse limitado a evaluar si la LDCP era inconstitucional. Más bien, la cuestión debería haber girado en torno a si la ley también era 'convencional'. Es decir, los tribunales de Barbados, incluso el CJCP y ahora la Corte de Justicia del Caribe, deben también decidir si la ley de Barbados restringe o viola los derechos reconocidos en la Convención. En este sentido, la Corte ha afirmado, en otras ocasiones, que 'el Poder Judicial debe ejercer una especie de 'control de convencionalidad' entre las normas jurídicas internas [...] y la Convención Americana sobre Derechos Humanos' [nota omitida]"'1.

Sin duda alguna, este fallo de la Corte IDH contiene un criterio de la mayor relevancia para la materia de este estudio. Sin embargo, es importante subrayar que los argumentos parecen referirse a la importancia de interpretar de forma amplia la competencia de los órganos nacionales, cuando está en juego la efec-

90 "El artículo 26 [nota omitida] de la Constitución de Barbados previene que tribunales puedan declarar la inconstitucionalidad de leyes existentes que hayan sido promulgadas antes de la entrada en vigor de la Constitución, esto es, antes del 30 de noviembre de 1966. Dicho artículo se conoce como una 'cláusula de exclusión' dado que no permite que dichas leyes se sometan a una revisión de constitucionalidad de normas, y por lo tanto, las 'excluye' de tal proceso [...]. Esta supuesta limitación al derecho a la protección judicial fue tratada en el año 2004 por el máximo tribunal de apelaciones de Barbados de aquél entonces, el Comité Judicial del Consejo Privado (en adelante, 'CJCP') el cual sostuvo en el caso Boyce y Joseph vs. La Reina que los tribunales internos no podían declarar que el artículo $2^{\circ}$ de la LDCP es inconsistente con el artículo 15.1 de la Constitución de Barbados, el cual prohíbe el trato inhumano o degradante, dado que la LDCP es una 'ley existente' conforme al significado del artículo 26 de la Constitución [nota omitida]. Sin embargo, el Comité Judicial del Consejo Privado asimismo manifestó [nota omitida] que, si no fuera por la cláusula de exclusión, hubiese declarado que la pena de muerte obligatoria va en contra del derecho constitucional de no ser sometido a una pena cruel, inhumana y degradante [nota omitida]. La Corte observa que el CJCP llegó a la conclusión mencionada anteriormente a través de un análisis puramente constitucional, en el cual no se tuvo en cuenta las obligaciones que tiene el Estado conforme a la Convención Americana y según la jurisprudencia de esta Corte". Corte Interamericana de Derechos Humanos. Boyce y otros Vs. Barbados (2007), párrs. 75-77.

91 Ibídem, párr. 78. 
tividad de los mecanismos procesales que tutelan los derechos humanos, más que a la necesidad de resolver una antinomia normativa entre una disposición constitucional y una norma convencional. Es decir, la Corte IDH requiere a las cortes nacionales interpretar sus facultades de forma amplia, de manera que puedan ejercer un control de convencionalidad sobre las leyes nacionales, pero no exige ejercer un control de constitucionalidad, a pesar de la cláusula de exclusión. Sobre el particular, la Corte IDH ordenó al Estado adoptar las medidas legislativas necesarias para reformar el artículo 26 de la Constitución de Barbados y habilitar, de esta forma, la facultad de las cortes nacionales para ejercer el control de constitucionalidad respectivo ${ }^{92}$.

En síntesis, si bien la Corte IDH se ha referido a la "aplicación de la norma más favorable" en múltiples ocasiones, el estudio detallado de los casos concretos revela una diversidad de ejercicios normativos que tienen como eje central la interpretación (expansiva o restrictiva, según sea el caso) del contenido y alcance de los derechos humanos. No parece haber, hasta el momento, un pronunciamiento preciso de la Corte IDH que sostenga la idea de la vertiente normativa, sin considerar otros aspectos del orden jurídico, incluido, por ejemplo, el principio de la supremacía constitucional. Más bien, existen muchos ejemplos del uso preciso e idóneo del principio pro persona como un criterio de interpretación que sienta las condiciones normativas más adecuadas para la efectiva protección de las personas.

En contraste, es importante hacer referencia a la posición asumida por la Corte IDH en el caso Artavia Murillo y otros contra Costa Rica. El problema jurídico en este asunto se originó en una sentencia de la Sala Constitucional de la Corte Suprema de Costa Rica. En la misma, dicha sala concluyó que el procedimiento de fertilización in vitro era incompatible con la protección al derecho a la vida, según se reconocía en artículo 4.1 de la $\mathrm{CADH}$. De manera relevante para este estudio, la Sala Constitucional concluyó que esta norma convención reconocía de forma más amplia el derecho a la vida, extendiendo la protección al momento de la concepción. En conclusión, el artículo referido resultaba ser la norma más favorable para la protección de vida de los embriones.

Frente a una posición inédita respecto al alcance del artículo 4.1 de la $\mathrm{CADH}$, la Corte IDH recurrió a todo el aparato interpretativo del DIDH para sostener un sentido distinto de esta disposición. Para fines de este análisis destacan, sin embargo, los argumentos propuestos por la Corte IDH respecto al "principio

92 Ibídem, párr. 127.c. 
de interpretación más favorable y el objeto y fin del tratado"93. En palabras del tribunal:

[l]os antecedentes que se han analizado hasta el momento permiten inferir que la finalidad del artículo 4.1 de la Convención es la de salvaguardar el derecho a la vida sin que ello implique la negación de otros derechos que protege la Convención [...]. En consecuencia, no es admisible el argumento del Estado en el sentido de que sus normas constitucionales otorgan una mayor protección del derecho a la vida y, por consiguiente, procede hacer prevalecer este derecho en forma absoluta [...]. [E]n aplicación del principio de interpretación más favorable, la alegada "protección más amplia" en el ámbito interno no puede permitir, ni justificar la supresión del goce y ejercicio de los derechos y libertades reconocidas en la Convención o limitarlos en mayor medida que la prevista en ella94.

Con este criterio, la Corte IDH parece reiterar, una vez más, que la selección de una norma presuntamente más protectora para un derecho humano en específico no puede entenderse sin una interpretación adecuada de la misma. La coexistencia de múltiples derechos, que pueden entrar en juego en el análisis de un caso concreto, demanda a las personas operadoras del sistema de justicia una visión integral de los problemas sociojurídicos, de forma que no se afecten de forma injustificada o desproporcionada el ejercicio de aquellos. En este sentido, el criterio establecido en la sentencia de fondo del caso Artavia Murillo y otros contra Costa Rica aporta nuevas luces al debate sobre la interacción entre las normas nacionales e internacionales que reconocen derechos humanos. Según se deriva del mismo, las cortes nacionales no pueden limitarse a identificar una disposición que, desde una lectura literal de la misma, parezca ampliar el contenido o ámbito de protección de un derecho, sin considerar el efecto práctico de dicha selección normativa. En este sentido, la interpretación de cada disposición tiene un papel fundamental para la correcta operación de las normas de derechos humanos, según se ha sostenido a lo largo de este artículo.

\section{CONClusiones}

En este artículo se propuso una revisión del concepto del principio pro persona, gestado desde la doctrina latinoamericana, a la luz del DIDH. La premisa del

93 Corte Interamericana de Derechos Humanos. Artavia Murillo y otros (Fecundación in vitro) Vs. Costa Rica (2012), sección C.4.

94 Ibídem, párrs. 258 y 259. 
análisis fue que la propia dinámica normativa que caracteriza la argumentación jurídica de los derechos humanos a nivel internacional podría tener un impacto sustantivo en la forma de concebir el principio en cuestión. Este examen es particularmente relevante considerando que el sustento jurídico del principio pro persona deviene, originalmente, de los propios tratados internacionales en derechos humanos.

Con base en la evidencia presentada en este trabajo, es posible reafirmar que el DIDH tiene una preferencia clara por la interpretación armónica de las disposiciones normativas relevantes, que contrasta con los ejercicios tradicionales de selección normativa del derecho nacional. En consecuencia, de conformidad con la lógica interna y práctica argumentativa del DIDH, sustentada en el análisis de la jurisprudencia latinoamericana, la tarea más importante de las cortes nacionales o internacionales será la correcta interpretación de las disposiciones convencionales, constitucionales o legales, con el fin de dar la respuesta más adecuada a los problemas concretos planteados en un caso particular.

Por el contrario, en la jurisprudencia interamericana no parecen existir bases para sostener una noción del concepto pro persona, la cual tenga como función principal o primaria la selección normativa, al menos no en los términos normalmente asociados con los problemas de las antinomias normativas. Lo anterior, incluso en aquellos casos en que las normas constitucionales puedan considerarse contrarias a una norma convencional. En estos supuestos, la práctica interamericana parecería apuntar más bien a la necesidad de modificar o reformar la norma en cuestión, atendiendo a los procesos legales establecidos para tales fines por el propio sistema, en línea con la obligación general de adoptar las medidas legislativas necesarias para adecuar el orden interno a los compromisos internacionales en materia de derechos humanos.

En este sentido, la jurisprudencia interamericana parece más cercana a la concepción inicial del principio pro persona propuesta por la jurista argentina Mónica Pinto. Como se señaló en su momento, el desarrollo conceptual planteado por esta autora se centraba en dos pautas distintas de actuación del Estado, i. e., hermenéutica y reglamentaria. Al igual que en los fallos de la Corte IDH, estas pautas sirven para que el diálogo internacional se dirija a las instituciones estatales, específicamente facultadas para atender los compromisos internacionales asumidos por los Estados.

En contraste con estas consideraciones, el concepto del principio pro persona que se ha expandido a través de la doctrina latinoamericana pretendidamente responde más a la lógica tradicional (formalista, incluso) que ha caracterizado 
la operación de los sistemas jurídicos en la región. Según se evidencia en la jurisprudencia interamericana, la selección de una norma no es suficiente para plantear soluciones concretas ante los problemas que surgen de la operación de las normas de derechos humanos en los contextos sociopolíticos actuales. Más aún, difícilmente se podría sostener que un derecho humano corresponde, incluso normativamente, a una disposición jurídica única, independiente o aislada. Por el contrario, la preferencia por la interpretación armónica, expansiva y evolutiva de los derechos implica reconocer que su contenido solo puede ser definido a través de la interacción de distintas disposiciones, sean nacionales y/o internacionales. Esta postura se confronta directamente con la lógica que ha guiado por décadas el análisis constitucional de las garantías individuales, al menos en el caso mexicano.

En síntesis, el análisis detallado de la práctica argumentativa de la Corte IDH, en tanto un ejemplo concreto de la operación DIDH, no sostiene la supuesta existencia de las dos vertientes del principio pro persona y, mucho menos, su supuesta aplicación secuencial. Por el contrario, la evidencia refuerza la importancia del uso correcto e integral de los principios de interpretación propios del DIDH. Esta es, al menos, una vía concreta a través de la cual la Corte IDH ha logrado desarrollar argumentos más complejos sobre el contenido de los derechos o el alcance de las obligaciones estatales, a fin de responder de forma más adecuada a los problemas concretos que se plantean en los casos.

En todo caso, es importante reconocer que, al situar el análisis del principio pro persona en el DIDH, tampoco se responde del todo a la pregunta sobre su operación a nivel interno. Según se enfatizó desde un inicio, este análisis se sustenta en la presunción de que el origen normativo del principio pro persona es el propio DIDH, por lo que su desarrollo conceptual debe responder a la lógica del sistema que lo origina. Frente a esta conclusión, es posible también cuestionar cómo debería concebirse el principio pro persona, si el mismo se sustenta exclusiva o primariamente en el orden jurídico interno. Esta es una cuestión pendiente, que excede el objetivo de este artículo.

El estudio propuesto en este artículo tiene implicaciones adicionales, que trascienden la discusión pormenorizada del principio pro persona. Como se apuntó al inicio del mismo, es importante considerar que la recepción del DIDH en los sistemas jurídicos nacionales no se limita a la incorporación de nuevas disposiciones normativas (convencionales), generadas a través de un procedimiento distinto al establecido por las disposiciones constitucionales. Por el contrario, un proceso integral de recepción del DIDH debe también considerar la forma en que sus principios estructurales o dinámicas de operación impactan, hasta el grado de 
poder transformar, la lógica tradicional con que los sistemas nacionales se han aproximado a la discusión jurídica de los derechos humanos.

El reto que implica esta propuesta no es menor, ni en términos teóricos ni prácticos. Sin embargo, el diálogo sustantivo entre distintos sistemas normativos debe plantearse en términos más profundos, a fin de generar espacios de protección genuinamente armónicos, sin tampoco desatender los contextos políticojurídicos nacionales. En otras palabras, la recepción del DIDH debe plantearse en términos de una sinergia de construcción evolutiva de la lógica tanto de los sistemas nacionales como del propio sistema internacional, reconociendo el impacto sustantivo de unos en los otros.

Más allá de estas conclusiones, es oportuno destacar, como corolario de este trabajo, que la interpretación expansiva de la Corte IDH es un ejercicio de argumentación normativa que no asegura per se la efectividad de los derechos en un contexto concreto. En otras palabras, la mera resolución de un tribunal no es suficiente, por sí misma, para lograr un cambio sustancial en la realidad de una persona o grupos de personas, en tanto a sus condiciones reales de vida. Lo anterior requerirá, como mínimo, una serie de acciones para operar de forma adecuada la resolución judicial. Más aún si las sentencias interamericanas tienen una vocación de transformación social y/o estructural, como ha llegado a sostener la Corte IDH, el paso de la argumentación jurídica a la efectividad de los derechos puede ser todavía más complejo. En todo caso, el debate de los derechos debe partir del reconocimiento amplio de su contenido. Solo de esta forma nos acercaremos a una verdadera cultura de la exigibilidad social, política a jurídica de los derechos humanos en nuestra región, con miras a transformar la realidad cotidiana de cada persona.

\section{BiBLIOGRAFÍA}

Aguilar Cavallo, Gonzalo (2016): "Principios de interpretación de los derechos fundamentales a la luz de la jurisprudencia chilena e internacional", en Boletín Mexicano de Derecho Comparado (Vol. 49, No 146), pp. 2448-4873.

CARPIO Marcos, Edgar (2004): La interpretación de los derechos fundamentales, (Lima, Palestra Editores).

CAstañeda, Mireya (2014): El principio pro persona. Experiencias y expectativas, (D.F. México, Comisión Nacional de Derechos Humanos).

Castilla, Karlos (2009): "El principio pro persona en la administración de justicia”, en Cuestiones Constitucionales (No 20), pp. 65-83. 
COMISIÓN DE DERECHO INTERNACIONAL (2006): Fragmentation of International Law: Difficulties Arising from the Diversification and Expansion of International Law. Report of the Study Group of the International Law Commission, A/CN.4/L.682.

HeNDERSON, Humberto (2004): "Los tratados internacionales de derechos humanos en el orden interno: la importancia del principio pro homine", en Revista Instituto Interamericano de Derechos Humanos (No 39), pp. 71-99.

JACOBS, Francis G. (1969): "Varieties of Approach to Treaty Interpretation: With Special Reference to the Draft Convention on the Law of Treaties before the Vienna Diplomatic Conference", en The International and Comparative Law Quarterly (Vol. 18, No 2), pp. 318-346.

Jenks, Wilfred (1953): “The Conflict of Law-Making Treaties”, en British Year Book of International Law, Vol. 30.

Koskenniemi, Martti, y Leino, Päivi (2002): "Fragmentation of International Law? Postmodern Anxieties", en Leiden Journal of International Law, (Vol. 15, No 3), pp. 553- 559.

PinTo, Mónica (1997): "El principio pro homine. Criterios de hermenéutica y pautas para la regulación de los derechos humanos”, en ABREgú, Martín, La aplicación de los tratados sobre derechos humanos por los tribunales locales (Buenos Aires, Centro de Estudios Legales y Sociales).

Quintana Osuna, Karla (2008) “Recognition of women's rights before the American Court of Human Rights: Developments", en Harvard Human Rights Journal (Vol. 21), pp. 1-12.

SAGÜÉS, Néstor Pedro (2004): "La interpretación de los derechos humanos en las jurisdicciones nacional e internacional”, en $A A$. $V V$. Derechos humanos y Constitución en Iberoamérica (Lima, Palestra Editores).

Simma, Bruno, y Pulkowski, Dirk (2006): "Of Planets and the Universe: Self-contained Regimes in International Law”, en The European Journal of International Law (Vol. 17, No 3), pp. 483-529.

\section{SENTENCIAS Y OPINIONES CONSULTIVAS DE LA}

Corte Interamericana de Derechos Humanos

Corte IDH. Propuesta de modificación a la Constitución Politica de Costa Rica relacionada con la naturalización. Opinión Consultiva OC-4/84 de 19 de enero de 1984. Serie A No 4. 
Corte IDH. La colegiación obligatoria de periodistas (Arts. 13 y 29 Convención Americana sobre Derechos Humanos). Opinión Consultiva OC-5/85 de 13 de noviembre de 1985. Serie A No 5.

Corte IDH. La expresión "Leyes" en el artículo 30 de la Convención Americana sobre Derechos Humanos. Opinión Consultiva OC-6/86 de 9 de mayo de 1986. Serie A No 6.

Corte IDH. Exigibilidad del Derecho de Rectificación o Respuesta (arts. 14.1, 1.1 y $2^{a}$ Convención Americana sobre Derechos Humanos). Opinión Consultiva OC-7/86 de 29 de agosto de 1986. Serie A No 7.

Corte IDH. El hábeas corpus bajo suspensión de garantías (Arts. 27.2, 25.1 y 7.6 Convención Americana sobre Derechos Humanos). Opinión Consultiva OC8/87 de 30 de enero de 1987. Serie A No 8.

Corte IDH. Garantias judiciales en estados de emergencia (Arts. 27.2, 25 y $8^{a}$ Convención Americana sobre Derechos Humanos). Opinión Consultiva OC-9/87 de 6 de octubre de 1987. Serie A No 9.

Corte IDH. Caso Loayza Tamayo Vs. Perú. Fondo. Sentencia de 17 de septiembre de 1997. Serie C No 33.

Corte IDH. Caso Ivcher Bronstein Vs. Perú. Competencia. Sentencia de 24 de septiembre de 1999. Serie C No 54.

Corte IDH. Caso del Tribunal Constitucional Vs. Perú. Competencia. Sentencia de 24 de septiembre de 1999. Serie C No 55.

Corte IDH. Caso Bámaca Velásquez Vs. Guatemala. Fondo. Sentencia de 25 de noviembre de 2000. Serie C No 70.

Corte IDH. Caso Baena, Ricardo y otros vs. Panamá, Fondo, Reparaciones y Costa, Sentencia de 2 de febrero de 2001. Serie C No 72.

Corte IDH. Caso "La Última Tentación de Cristo" (Olmedo Bustos y otros) vs. Chile. Fondo, Reparaciones y Costas. Sentencia de 5 de febrero de 2001. Serie C No 73.

Corte IDH. Caso Las Palmeras vs. Colombia. Fondo. Sentencia de 6 de diciembre de 2001. Serie C No 90.

Corte IDH. Caso Cinco Pensionistas vs. Perú. Fondo, Reparaciones y Costas. Sentencia de 28 de febrero de 2003. Serie C No 98.

Corte IDH. Caso 19 Comerciantes vs. Colombia. Fondo, Reparaciones y Costas. Sentencia de 5 de julio de 2004. Serie C No 109.

Corte IDH. Caso Ricardo Canese vs. Paraguay. Fondo, Reparaciones y Costas. Sentencia de 31 de agosto de 2004. Serie C No 111. 
Corte IDH. Caso Comunidad Indigena Yakye Axa Vs. Paraguay. Fondo Reparaciones y Costas. Sentencia 17 de junio de 2005. Serie C No 125.

Corte IDH. Caso de la Masacre de Mapiripán Vs. Colombia. Fondo, Reparaciones y Costas. Sentencia de 15 de septiembre de 2005. Serie C No 134.

Corte IDH. Caso de las Masacres de Ituango Vs. Colombia. Sentencia de 1 de julio de 2006. Serie C No 148.

Corte IDH. Caso Ximenes Lopes Vs. Brasil. Fondo, Reparaciones y Costas. Sentencia de 4 de julio de 2006. Serie C No 149.

Corte IDH. Caso del Penal Miguel Castro Castro Vs. Perú. Fondo, Reparaciones y Costas. Sentencia de 25 de noviembre de 2006. Serie C No 160.

Corte IDH. Caso Boyce y otros vs. Barbados. Excepción Preliminar, Fondo, Reparaciones y Costas. Sentencia de 20 de noviembre de 2007. Serie C No 169.

Corte IDH. Caso Apitz Barbera y otros ("Corte Primera de lo Contencioso Administrativo”) Vs. Venezuela. Excepción Preliminar, Fondo, Reparaciones y Costas. Sentencia de 5 de agosto de 2008. Serie C No 182.

Corte IDH. Caso Herrera Ulloa vs. Costa Rica, Excepciones Preliminares, Fondo, Reparaciones y Costas, Sentencias de 2 de julio de 2004. Serie C No 107, párr. 184.

Corte IDH. Caso González y otras (“Campo Algodonero") Vs. México. Excepción Preliminar, Fondo, Reparaciones y Costas. Sentencia de 16 de noviembre de 2009. Serie C No 205.

Corte IDH. Caso Radilla Pacheco vs. México, Excepciones Preliminares, Fondo, Reparaciones y Costas, Sentencia de 23 de noviembre de 2009. Serie C No 209. Corte IDH. Caso Fernández Ortega y otros Vs. México. Excepción Preliminar, Fondo, Reparaciones y Costas. Sentencia de 30 de agosto de 2010. Serie C No 215. Corte IDH. Caso Rosendo Cantú y otra Vs. México. Excepción Preliminar, Fondo, Reparaciones y Costas. Sentencia de 31 de agosto de 2010. Serie C No 216. Corte IDH. Caso Cabrera García y Montiel Flores Vs. México. Excepción Preliminar, Fondo, Reparaciones y Costas. Sentencia de 26 de noviembre de 2010. Serie C No 220.

Corte IDH. Caso Atala Riffo y niñas Vs. Chile. Fondo, Reparaciones y Costas. Sentencia del 24 de febrero de 2012. Serie C No 239.

Corte IDH. Caso Pueblo Indígena Kichwa de Sarayaku Vs. Ecuador. Fondo y reparaciones. Sentencia de 27 de junio de 2012. Serie C No 245. 
Corte IDH. Caso Artavia Murillo y otros ("Fecundación in vitro") Vs. Costa Rica. Excepciones Preliminares, Fondo, Reparaciones y Costas Sentencia de 28 noviembre de 2012. Serie C No 257.

Corte IDH. Caso Masacre de Santo Domingo Vs. Colombia. Excepciones Preliminares, Fondo y Reparaciones. Sentencia de 30 de noviembre de 2012. Serie C No 259.

Corte IDH. Caso Suárez Peralta Vs. Ecuador. Excepciones Preliminares, Fondo, Reparaciones y Costas. Sentencia de 21 de mayo de 2013. Serie C No 261.

Corte IDH. Caso de personas dominicanas y haitianas expulsadas Vs. República Dominicana. Excepciones Preliminares, Fondo, Reparaciones y Costas. Sentencia de 28 de agosto de 2014. Serie C No 282.

Corte IDH. Caso Cruz Sánchez y otros Vs. Perú. Excepciones Preliminares, Fondo, Reparaciones y Costas. Sentencia de 17 de abril de 2015. Serie C No 292.

Corte IDH. Caso López Lone y otros Vs. Honduras. Excepción Preliminar, Fondo, Reparaciones y Costas. Sentencia de 5 de octubre de 2015. Serie C No 302. Corte IDH. Caso Quispialaya Vilcapoma Vs. Perú. Excepciones Preliminares, Fondo, Reparaciones y Costas. Sentencia de 23 de noviembre de 2015. Serie C No 308.

Corte IDH. Caso Duque Vs. Colombia. Excepciones Preliminares, Fondo, Reparaciones y Costas. Sentencia de 26 de febrero de 2016. Serie C No 310. Corte IDH. Caso Pollo Rivera y otros Vs. Perú. Fondo, Reparaciones y Costas. Sentencia de 21 de octubre de 2016. Serie C No 319.

Corte IDH. Caso Duque Vs. Colombia. Resolución de la Corte Interamericana de Derechos Humanos 26 de febrero de 2016. Serie C No 322.

\section{INSTRUMENTOS INTERNACIONALES}

Código de conducta para funcionarios encargados de hacer cumplir la ley (1979). Convención de Viena sobre Derecho de los Tratados (1969).

Convención Americana sobre Derechos Humanos (1969).

Declaración Americana de Derechos y Deberes del Hombre (1948).

Declaración sobre la Utilización del Progreso Científico y Tecnológico en Interés de la Paz y en Beneficio de la Humanidad (1975).

Pacto Internacional de Derechos Económicos, Sociales y Culturales (1966).

Principios Básicos sobre el Empleo de la Fuerza y de Armas de Fuego por los Funcionarios Encargados de Hacer Cumplir la Ley (1990). 